\title{
Overexpression of wild type RRAS2, without oncogenic mutations, drives chronic lymphocytic leukemia
}

\author{
Alejandro M. Hortal ${ }^{1 \dagger}$, Clara L. Oeste ${ }^{1,2^{*} \dagger}$, Claudia Cifuentes ${ }^{1 \dagger}$, Miguel Alcoceba ${ }^{3}$, Isabel Fernández-Pisonero ${ }^{4}$, \\ Laura Clavaín ${ }^{4}$, Rut Tercero ${ }^{1}$, Pilar Mendoza ${ }^{1}$, Verónica Domínguez ${ }^{5}$, Marta García-Flores ${ }^{5}$, Belén Pintado ${ }^{5}$ \\ David Abia ${ }^{6}$, Carmen García-Macíass ${ }^{4}$ Almudena Navarro-Bailón ${ }^{3}$, Xosé R. Bustelo ${ }^{4}$, Marcos González ${ }^{3}$ and \\ Balbino Alarcón ${ }^{1 *}$ (1)
}

\begin{abstract}
Background: Chronic lymphocytic leukemia (CLL) is the most frequent, and still incurable, form of leukemia in the Western World. It is widely accepted that cancer results from an evolutionary process shaped by the acquisition of driver mutations which confer selective growth advantage to cells that harbor them. Clear examples are missense mutations in classic RAS genes (KRAS, HRAS and NRAS) that underlie the development of approximately 13\% of human cancers. Although autonomous B cell antigen receptor (BCR) signaling is involved and mutations in many tumor suppressor genes and oncogenes have been identified, an oncogenic driver gene has not still been identified for CLL.

Methods: Conditional knock-in mice were generated to overexpress wild type RRAS2 and prove its driver role. RTqPCR analysis of a human CLL sample cohort was carried out to measure RRAS2 transcriptional expression. Sanger DNA sequencing was used to identify a SNP in the 3'UTR region of RRAS2 in human CLL samples. RNAseq of murine CLL was carried out to identify activated pathways, molecular mechanisms and to pinpoint somatic mutations accompanying RRAS2 overexpression. Flow cytometry was used for phenotypic characterization and shRNA techniques to knockdown RRAS2 expression in human CLL.

Results: RRAS2 mRNA is found overexpressed in its wild type form in $82 \%$ of the human CLL samples analyzed ( $n=178$, mean and median $=5$-fold) as well as in the explored metadata. A single nucleotide polymorphism ( $\mathrm{r} 85570)$ in the 3'UTR of the RRAS2 mRNA has been identified in CLL patients, linking higher expression of RRAS2 with more aggressive disease. Deliberate overexpression of wild type RRAS2 in mice, but not an oncogenic Q72L mutation in the coding sequence, provokes the development of CLL. Overexpression of wild type RRAS2 in mice is accompanied by a strong convergent selection of somatic mutations in genes that have been identified in human CLL. R-RAS2 protein is physically bound to the BCR and mediates BCR signals in CLL.
\end{abstract}

Conclusions: The results indicate that overexpression of wild type RRAS2 is behind the development of CLL.

\footnotetext{
*Correspondence: claraloeste@gmail.com; balarcon@cbm.csic.es

${ }^{\dagger}$ Alejandro M. Hortal, Clara L. Oeste and Claudia Cifuentes contributed equally to this work.

${ }^{1}$ Immune System Development and Function Program, Centro Biología Molecular Severo Ochoa, Consejo Superior de Investigaciones Científicas, Universidad Autónoma de Madrid, 28049 Madrid, Spain

2 Savana, S.L., Calle Gran Vía 30, 28013 Madrid, Spain

Full list of author information is available at the end of the article
}

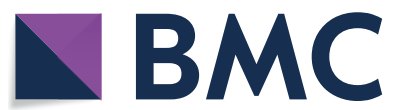

(c) The Author(s) 2022. Open Access This article is licensed under a Creative Commons Attribution 4.0 International License, which permits use, sharing, adaptation, distribution and reproduction in any medium or format, as long as you give appropriate credit to the original author(s) and the source, provide a link to the Creative Commons licence, and indicate if changes were made. The images or other third party material in this article are included in the article's Creative Commons licence, unless indicated otherwise in a credit line to the material. If material is not included in the article's Creative Commons licence and your intended use is not permitted by statutory regulation or exceeds the permitted use, you will need to obtain permission directly from the copyright holder. To view a copy of this licence, visit http://creativecommons.org/licenses/by/4.0/. The Creative Commons Public Domain Dedication waiver (http://creativeco mmons.org/publicdomain/zero/1.0/) applies to the data made available in this article, unless otherwise stated in a credit line to the data. 
Keywords: RRAS2, RAS proteins, B cells, Lymphoid malignancies, Chronic lymphocytic leukemia, B cell receptor, PI3K pathway

\section{Background}

B-Cell Chronic Lymphocytic Leukemia (CLL) is the most common cause of leukemia in the Western world and accounts for one-third of new cases of leukemia each year $[1,2]$. CLL diagnosis requires the presence of $\geq 5 \times 10^{9} / \mathrm{L}$ monoclonal B cells in the peripheral blood with a typical morphology (mature lymphocytes with scarce cytoplasm) and immunophenotype (CD19+/ CD5+/CD23+/CD200+) [2]. In cases without lymphadenopathy or organomegaly, a B lymphocyte count below the given level is described as monoclonal B lymphocytosis (MBL). MBL has been found to progress to CLL at a rate of $1-2 \%$ per year [3]. CLL has a very heterogeneous clinical course, including patients with a stable form of the disease without treatment requirement, whereas others develop an aggressive form of CLL. Some clinical/biological (male sex, age $>60$ years, advanced clinical stage, higher absolute lymphocyte count, high levels of serum $\beta 2$-microglobulin and LDH) as well as cytogenetic and molecular characteristics (presence of del (17p) and/or TP53 mutations, presence of $\operatorname{del}(11 \mathrm{q})$, and unmutated IGHV gene have been associated to poor prognosis [3, 4].

The molecular mechanisms underlying CLL have been the subject of extensive research for decades, though their highly dynamic nature and dependence on treatment outcomes often preclude their full elucidation [5]. BCR signaling is crucial in CLL, as evidenced by the dichotomy of disease evolution dependent on BCR mutation status, i.e., IGHV-UM or IGHV-M forms. The involvement of BCR signaling in CLL is also highlighted by current treatments, which focus on inhibiting BCRassociated kinases. Such is the case for ibrutinib, which inhibits Bruton's tyrosine kinase (BTK), fosfamatinib, inhibiting spleen tyrosine kinase (SYK), or idelalisib, which targets the hematopoietically expressed PI3K $\delta$ [6]. Indeed, PI3K $\delta$, a downstream player in R-RAS2 signaling, is overexpressed in CLL [7]. Clones of IGHV-M and IGHV-UM B cells are thought to be selected and expand in response to high or low affinity autoantigens, respectively [6]. Notably, BCR signaling in CLL has also been described as cell-autonomous, independent of antigen stimulation and dependent on the heavy chain complementarity-determining region 3 (CDR3) and an internal epitope [8]. This mode of pathogenic signaling points to the importance in CLL of tonic BCR signaling. Repeated BCR stimulation also upregulates CD5 expression, a phenotypic marker for CLL [9].
RAS proteins comprise a family of small guanosine triphosphate hydrolases (GTPases) that include wellknown oncogenic players such as K-RAS, H-RAS and N-RAS. The RAS-related subfamily of RAS proteins (R-RAS) are approximately $55-60 \%$ identical to their classic counterparts and share factors that mediate their activation-inactivation cycles, i.e. guanine nucleotide exchange factors (GEFs) and GTPase-activating proteins (GAPs). Therefore, they also potentially share activating signals and cascades with classic RAS proteins. Early studies have shown that oncogenic mutations in R-RAS2 have equal or even higher transformation capacities than its classic RAS protein homologs [10, 11]. The overlapping signaling entities and transforming activity of different RAS proteins could suggest redundancy in RAS protein functions, as was found in studies using mice bearing null alleles of RAS family members. However, over the last decades, assays using double or triple knockout mice and other approaches have clarified the precise involvement of distinct RAS proteins in several processes. Specifically, R-RAS2 has been set forth as an important player in immunological development and homeostasis. R-RAS2 binds to antigen receptors on B and T cells (BCR and TCR, respectively) through their immune Receptor Tyrosine Activation Motifs (ITAMs) and mediates tonic signaling from these key hubs, mainly via PI3K pathways [12]. Downstream of PI3K, R-RAS2 can propagate signals intracellularly through Akt and NFkB [13]. In B cells, we previously showed that R-RAS2, as an effector of the $B C R$, is required for an efficient germinal center reaction by regulating B cell metabolism [14].

Additionally to its roles in immune homeostasis, R-RAS2 also mediates correct mammary gland development [15], and mutations in RRAS2 induce breast tumorigenesis and late-stage metastasis [16]. However, a striking early finding was that not only oncogenic mutations, but rather overexpression of the wild-type, unmutated form of RRAS2 induced breast cancer cell line transformation, as well [17]. Since then, many studies on different types of cancer have reported elevated R-RAS2 levels in human samples, including esophageal tumors [18], oral cancers [19] skin cancers [20] and lymphomas [12]. In spite of frequently finding RRAS2 mRNA and/ or protein overexpressed in human cancers, a causal relationship has not been clearly established. Here, we investigate whether overexpression of wild type RRAS2, i.e., without activating mutations, drives the development of malignancies in mice and if there is a correlation 
with human disease. We find that RRAS2 overexpression causes CLL in mice and could drive the development of CLL in the majority of human patients.

\section{Materials and methods \\ Mice}

The Rosa26-RRAS2 $2^{f l f l}$ knock-in mouse line was generated with genOway technologies, inserting by homologous recombination the cassette indicated in Fig. 1A in the Rosa26 locus. This construct is based on the CTV vector (a gift from Klaus Rajewsky; Addgene plasmid \# 15912; http://n2t.net/addgene:15912; RRID:Addgene_15,912) [21], and contains the wild-type sequence of human RRAS2 with an HA-tag under a CAG promoter, followed by EGFP after an IRES sequence and a LoxP-flanked stop codon (Rosa26-RRAS2 ${ }^{f l f f}$ ) at the $5^{\prime}$ end of the construct (Fig. S1b and Suppl. File 1). This mouse line was crossed with different Cre recombinase lines, generating conditional overexpression systems by removing the stop codon in specific tissues. We first set out to study systemic RRAS2 overexpression using Sox2-Cre mice, where Sox2 is an embryonic stem cell transcription factor and therefore induces deletion of the LoxP-flanked sequence in all tissues. Previously described Sox2-Cre and mb1Cre transgenic mouse lines were gently provided by Dr. César Cobaleda (CBM, Madrid) and Prof. Dr. Michael Reth (University of Freiburg, Germany) [22, 23]. We next generated the Rosa26-RRAS2 $2^{f l f l} \mathrm{xmb1-Cre} \mathrm{B-cell-specific}$ $R R A S 2$ overexpressing mouse line by crossing Rosa26$R R A S 2^{f l f l}$ mice with mb1-Cre mice, which express Cre recombinase specifically in B cells starting at an early precursor phase. Rras2 $(\mathrm{Q} 72 \mathrm{~L})^{\mathrm{f} / \mathrm{fl}} \mathrm{xmb} 1-\mathrm{Cre}$ mice were generated by crossing mb1-Cre mice with $\operatorname{Rras} 2(\mathrm{Q} 72 \mathrm{~L})^{\mathrm{f} /}$ fl mice which have a duplicated and inverted Exon 3 (bearing the Q72L) mutation in addition to the wild type Exon 3. Cre expression leads to swapping Exon 3 and the expression of the mutant Rras2 (Fernandez-Pisonero et al., under revision). Adoptive transfer experiments were performed in a CD45.1 mouse strain. This line was gently provided by Prof. Dr. Carlos Ardavín (CNB, Madrid) [24]. In vivo xenograft tumor growth assay with
MEC-1 cells was performed with the immunodeficient Rag $2^{-I-} \mathrm{\gamma c}^{-1-}$ mouse strain [25], purchased from Jackson Laboratories. All mice were maintained under SPF conditions at the animal facility of the Centro de Biología Molecular Severo Ochoa in accordance with national and European guidelines. All the procedures were approved by the ethical committee of the Centro de Biología Molecular Severo Ochoa and were under the Community of Madrid authorization numbers PROEX 384/15 and PROEX 296.7/21.

\section{Human cells}

Human blood samples were obtained from the Center for Blood Transfusions of the 'Comunidad de Madrid' where donations were obtained from healthy volunteers after providing their informed consent. Likewise, samples from volunteer CLL patients were obtained from the Hematology Unit of the Salamanca University Hospital after providing written informed consent. Authorization number PI 2019 03217. Fresh human PMBCs were obtained by density centrifugation in a Lymphoprep ${ }^{\text {TM }}$ (StemCell technologies) gradient of whole blood for flow cytometry and RT-qPCR analysis.

\section{Antibodies and reagents}

Antibodies used were: anti-mouse IgM-, IgD-, CD21-, CD23-, B220-, CD45R-V450 -biotin -APC, CD11c(HL3), CD3- (145-2C11), CD4-, CD8a-, Gr1- (RB68C5) and NK1.1- (RA3-6B2) -biotin, CD5-PE (53-7.3), CD11b-PerCP-Cy5.5 (M1/70), purified CD16/32 (2,4G2), CD19-PE-Cy7 (1D3), CD45.1 -APC-Cy7 (A20), CD45.2 -APC (104), and AlexaFluor ${ }^{\circledR} 647$ pBtk (Y223) from BD Pharmingen; anti-human RRAS2 from Abnova, anti-human $\beta$-Actin from Sigma-Aldrich (A228), antimouse F4/80 -biotin (BM8), from eBioscience; rabbit anti-mouse pERK (T202/Y204) (9101L), pAKT (S473) (4060L), pS6 (S240) (5364S), p4EBP1 (T37/46) (236B4), and pBLNK (Y96) from Cell Signalling; pVAV (Y174) (EP510Y) from Abcam, anti-IgM from Jackson Immunoresearch and anti-HA (12CA5) from Sigma.

\footnotetext{
(See figure on next page.)

Fig. 1 Overexpression of the unmutated RRAS2 leads to a B cell leukemia in mice. $\mathbf{a} \& \mathbf{b}$ Genomic alterations in the KRAS and RRAS2 genes according to cBioportal for cancer genomics (http://www.cbioportal.org). Data represent a combined study of 78,278 patients/81072 samples. The $X$-axis represents alteration frequency of the gene (colors represent the alteration type). The Y-axis represents different cancer types. $\mathbf{c}$ Relative mRNA expression of RRAS2 in different cancers. Data are represented in log2 scale and were obtained from the Pan-Cancer Analysis of Whole Genomes (PCAWG). $\mathbf{d}$ Representative images of the relative sizes of spleens from 12 month-old control and Sox2-Cre + mice. e Quantification of the total number of B cells per spleen of 6 month-old control and Sox2-Cre + mice. Data shown correspond to triplicate measurements of one control and three Sox2-Cre mice. Unpaired t-test with Welch's correction. $\mathbf{f}$ Hematoxylin and eosin images of the spleen structure in an 8-month old control mouse and in 4-, 8- and 12-month-old Sox2-Cre + mice. $\mathbf{g}$ Two-parameter flow cytometry of the expression of CD21 and CD23, and IgD and lgM, respectively, in B cells in spleens of 8 month-old control and Sox 2 Cre + mice $\mathbf{h}$ Left, two-parameter flow cytometry of the expression of CD5 and $\operatorname{lgM}$ in B cells of the blood of 8 month-old control and Sox2-Cre + mice. $\mathbf{i}$, quantification of the number of CD5 + IgM+ B cells in the blood of 40 wk-old control and Sox2-Cre + mice. Data shown correspond to duplicate measurements of four control and six Sox2-Cre mice. Unpaired t-test with Welch's correction. In all figures, control mice refer to Rosa26-RRAS2 $2^{\text {f/fl }}$ without Cre recombinase
} 


\section{a}

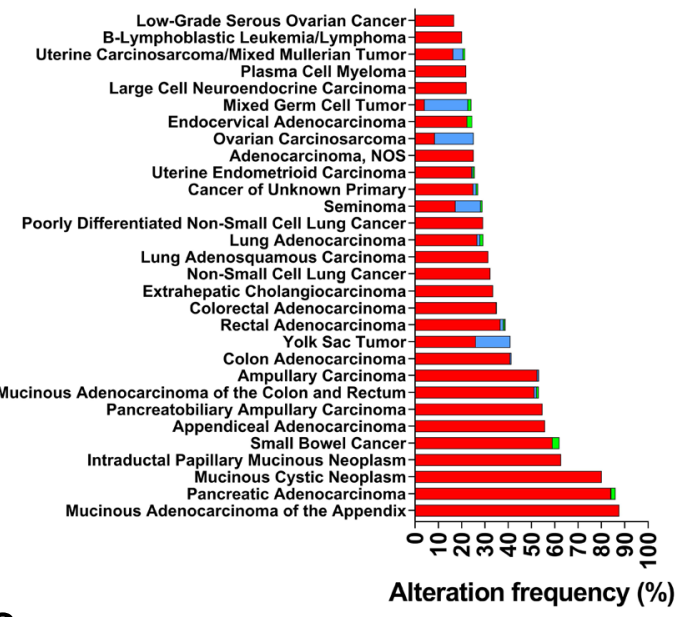

C

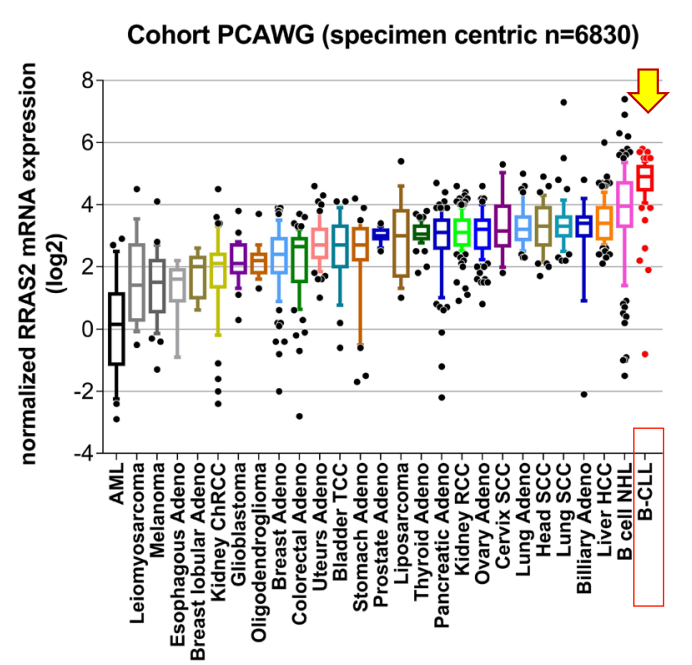

g
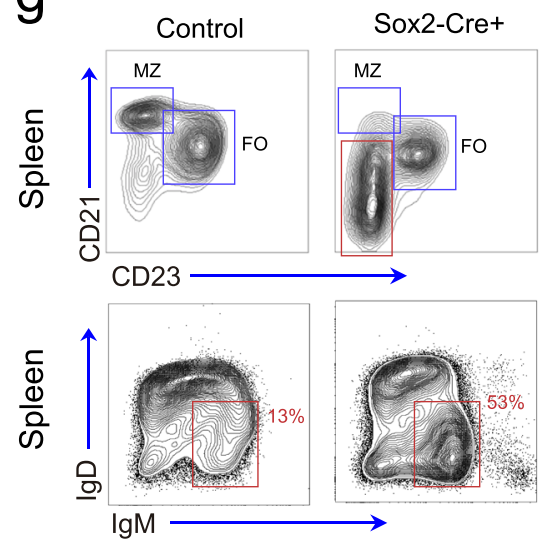

KRAS

d

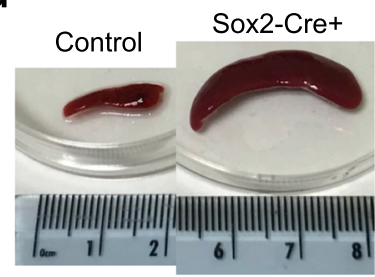

f

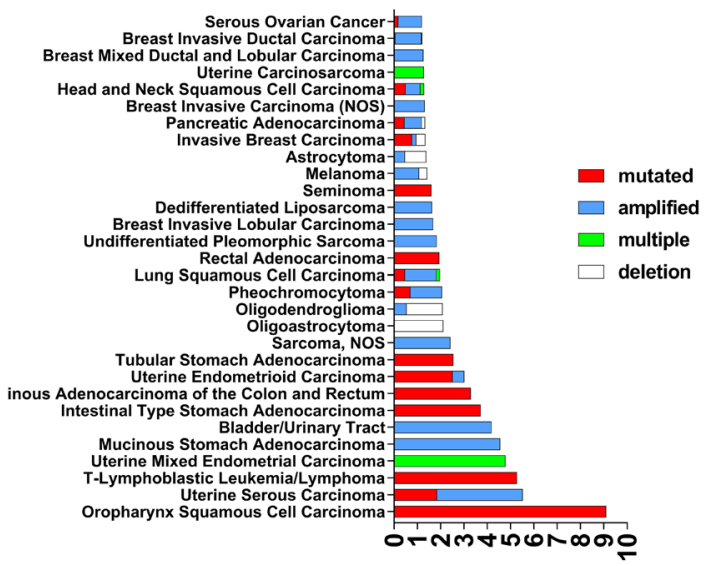

Alteration frequency (\%) e Total B cells

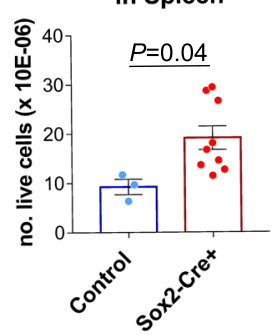

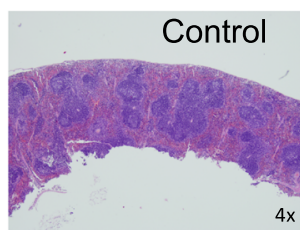

$8 \mathrm{mo}$.
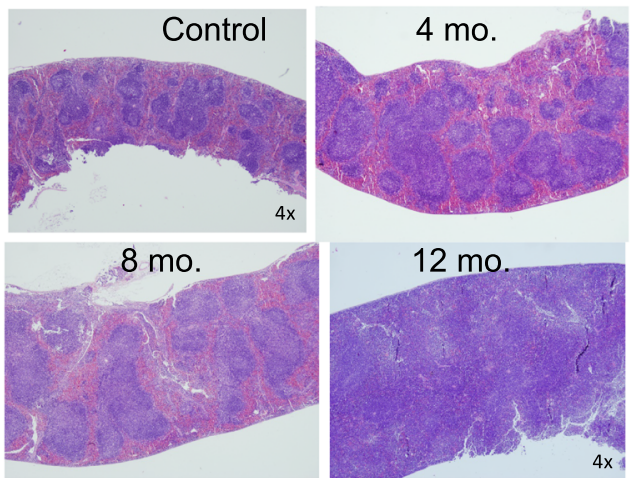

$12 \mathrm{mo}$.
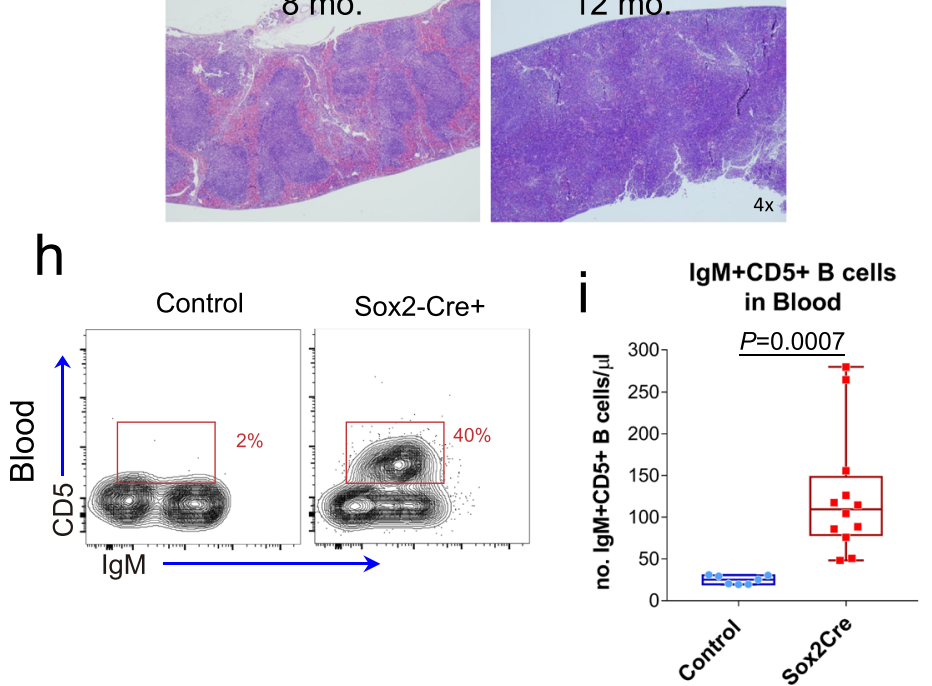

Fig. 1 (See legend on previous page.) 


\section{Cell preparation}

Spleen, lymph nodes and liver from mice of varied ages were homogenized with $40 \mu \mathrm{m}$ strainers and washed in phosphate-buffered saline (PBS) containing $2 \%(\mathrm{v} / \mathrm{v})$ fetal bovine serum (FBS). Spleen cells were resuspended for $3 \mathrm{~min}$ in AcK buffer $\left(0.15 \mathrm{M} \mathrm{NH}_{4} \mathrm{Cl}, 10 \mathrm{mM} \mathrm{KHCO}\right.$, $0.1 \mathrm{mM}$ EDTA, pH7.2-7.4) to lyse the erythrocytes and washed in PBS 2\% FBS. For in vitro cultures, cells were maintained in RPMI with $10 \%$ FBS supplemented with $2 \mathrm{mML}$-glutamine, $100 \mathrm{U} / \mathrm{ml}$ penicillin, $100 \mathrm{U} / \mathrm{ml}$ streptomycin, $20 \mu \mathrm{M} \beta$-mercaptoethanol and $10 \mathrm{mM}$ sodium pyruvate.

\section{Flow cytometry}

Mouse single-cell suspensions were incubated with fluorescently labelled antibodies for $30 \mathrm{~min}$ at $4{ }^{\circ} \mathrm{C}$ after blocking FC receptors using anti-CD16/32 antibody for $20 \mathrm{~min}$ at $4{ }^{\circ} \mathrm{C}$. Afterwards, cells were washed in PBS $+2 \%$ FBS and data were collected on a FACS Canto II (Becton Dickinson) cytometer. A minimum of 50,000 and a maximum of 200,000 events was acquired in every measurement. Analyses were performed using FlowJo software (TreeStar). Counting of total cells was performed with CountBright ${ }^{\mathrm{TM}}$ beads. For Phosflow assays, cells were first stained with extracellular antibodies, and then fixed by adding paraformaldehyde to a final concentration of $2 \%$ for $20 \mathrm{~min}$ at $4{ }^{\circ} \mathrm{C}$. After two washes, cells were permeabilized for $30 \mathrm{~min}$ with $90 \%$ methanol on ice. Intracellular labelling was performed at $4{ }^{\circ} \mathrm{C} \mathrm{O} / \mathrm{N}$ with specific phospho-Abs and their corresponding secondary antibodies. For Phosflow assays of the MEC-1 cell line, cells were first serum-starved and treated with specific inhibitors of MAPK extracellular signaling-regulated kinase (ERK) kinase (MEK), U0126 (Promega), phosphatidylinositol 3 kinase (PI3K), wortmannin (Millipore), idelalisib (MedChemExpress) and LY294002 (Sigma), mTOR complex Rapamycin (Millipore), Btk inhibitor Ibrutinib (MedChemExpress) and Src tyrosine kinases family PP2 (Sigma). After $6 \mathrm{~h}$, cells were treated as previously described.

\section{Adoptive cell transfer}

C57BL $/ 6$ CD $45.1^{+}$mice were sublethally irradiated with 0.6 Gy $6 \mathrm{~h}$ prior to cell transfer. Splenocytes from Rosa26$R R A S 2^{f l / f l} \mathrm{xmb} 1$-Cre mice were prepared as described above and $\mathrm{B}$ cells were negatively selected by magnetic bead separa tion using a cocktail of biotinylated antibodies (anti-CD3, anti-CD4, anti-CD8, anti-NK1.1., antiGr1, anti-F4/80 and anti-CD11c) followed by incubation with streptavidin-Dynabeads (Invitrogen). Recipient mice were injected intravenously in the tail vein with 5 million purified B cells per mouse. Mice were bled periodically from the facial vein and cells were stained and analyzed by flow cytometry.

\section{Lentivirus production and generation of MEC-1 RRAS2 knockdown cell line}

Lentiviral particles were generated in HEK293T cells cultured in DMEM with L-glutamine $2 \mathrm{mM}$ and $10 \%$ fetal bovine serum. Cells were transfected with $1.7 \mu \mathrm{g}$ pMD2.G, $3.3 \mu \mathrm{g}$ psPAX2 and $5 \mu \mathrm{g}$ of lentiviral vector (MISSION $^{\circledR}$ pLKO.1-puro GFP shRNA, Sigma; target sequence 5'-CGTGATGAGTTCCCAATGATT-3') in jet$\mathrm{PEI}^{\circledR}$. Supernatants were collected and filtered through $0.45 \mu \mathrm{m}$ filters (Sartorius) 24 and $48 \mathrm{~h}$ later. Transduction of MEC-1 cells was performed with Polybrene (Sigma) at $4 \mu \mathrm{g} / \mathrm{ml}$ by centrifugation at $900 \times \mathrm{g}$ at $32^{\circ} \mathrm{C}$ for $70 \mathrm{~min}$ without break. Cells were selected in $2.5 \mu \mathrm{g} / \mathrm{ml}$ puromycin $24 \mathrm{~h}$ after infection.

\section{Cell proliferation assay}

MEC-1 cells were plated into 24 well plates at the density of 50,000 cells/well. Cells were cultured for 6 days and cell growth was measured in a FACS Canto II using $1 \mu \mathrm{g} / \mathrm{ml}$ DAPI (Sigma) as viability dye and CountBright ${ }^{\mathrm{TM}}$ Absolute Counting Beads (Invitrogen) for cell count.

\section{Xenograft tumor growth assay}

Ten-week Rag $2^{-1-} \mathrm{\gamma c}^{-/-}$male mice were subcutaneously injected in their left flank with $10 \times 10^{6}$ MEC-1 control or MEC-1 RRAS2 knockdown cells as described in [26], in a mixture with PBS/Matrigel (1:1) (Becton Dickinson). Tumor growth was measured using a caliper, and mice were monitored to avoid unnecessary discomfort according to the ethical guidelines. At the endpoint of the experiment, all mice were sacrificed by $\mathrm{CO}_{2}$ inhalation.

\section{Immunoprecipitation and Western blotting}

For Western blotting of whole-cell lysates, GFP ${ }^{\text {low }}$ and $\mathrm{GFP}^{\text {high }}$ populations from Rosa26-RRAS2 $2^{f / f l} \mathrm{xmb1-Cre}$ mice and splenic B cells from control mice were sorted. Cells were then lysed in Brij96 lysis buffer with protease and phosphatase inhibitors $(0.5 \%$ Brij $96,140 \mathrm{mM}$ $\mathrm{NaCl}, 20 \mathrm{mM}$ tris- $\mathrm{HCl}$ (pH7.8), $10 \mathrm{mM}$ iodoacetamide, $1 \mathrm{mM}$ PMSF (phenylmethylsulfonyl fluoride), leupeptin $(1 \mathrm{mg} / \mathrm{ml})$, aprotinin $(1 \mathrm{mg} / \mathrm{ml}), 1 \mathrm{mM}$ sodium orthovanadate, and $20 \mathrm{mM}$ sodium fluoride). The samples were then resolved by SDS-polyacrylamide gel electrophoresis (PAGE) and analyzed by Western blotting with anti-human RRas2 from Abnova and anti-human $\beta$-Actin from Sigma-Aldrich. For immunoprecipitation, CD19+CD5+ leukemic cells from spleens of Rosa26RRAS2 $2^{f l f l} \mathrm{xmb} 1-\mathrm{Cre}$ mice were purified by negative selection using a biotin-labelled antibody cocktail and 
Streptavidin-coupled Dynabeads ${ }^{\circledR}$ (Invitrogen). Plasma membrane proteins of purified CD19+CD5+ leukemic cells were biotin-labelled using the membrane-impermeable biotinylation reagent Ez-Link SULFO-NHS-LC-Biotin (ThermoFisher). Biotinylated cells were then lysed in Brij96 lysis buffer for $30 \mathrm{~min}$ on ice and immunoprecipitation was carried out by incubation of cytosolic fraction with $7 \mu \mathrm{g}$ of anti-HA (12CA5) previously bound to Protein G Sepharose ${ }^{\circledR}$ beads (Sigma) under continuous rotation at $4{ }^{\circ} \mathrm{C}$ overnight. Beads were collected and washed five times with Brij96 lysis buffer and finally resuspended in $20 \mu \mathrm{L}$ of Laemmli buffer for two-dimensional SDSPAGE under non-reducing/reducing conditions. Immunoblotting was carried out with streptavidin-peroxidase (Sigma) for identification of total membrane proteins associated with RRAS2, with anti-mouse IgM (Jackson Immunoresearch) and anti-RRAS2 from Abnova.

\section{Real-time PCR}

RNA from peripheral blood mononuclear cells (PBMCs) of CLL patients or Rosa26-RRAS2 $2^{\mathrm{fl} / \mathrm{fl}}$ mb1Cre sorted mouse splenocytes (GFP ${ }^{\text {low }}$ vs. GFP ${ }^{\text {high }}$ ) was isolated using the RNAeasy Plus Mini Kit (QIAGEN). cDNA was synthesized with SuperScript III (Invitrogen) using Oligo-dT primers. Quantitative real-time PCR was performed in triplicate using $100 \mathrm{ng} \mathrm{cDNA}$ as template and the reverse transcription reaction with SYBR Green PCR Master Mix and gene-specific primers in an ABI 7300 Real Time PCR System. A set of primers was used to measure mRNA expression of RRAS2 exclusively in human cells (Forward: GCAGGACAAGAAGAGTTT GGA; Reverse: TCATTGGGAACTCATCACGA). A different set of primers was used to measure mRNA expression of combined human (RRAS2) and mouse (Rras2) origin (Forward: GAGTTTGGAGCCATGAGAGA; Reverse: CCTTTACTCTGAGAATCTGTCTTTGA). Both sets of primers expanded exons 3 and 4 in mouse and human mRNA. Obtained cycle threshold $(\mathrm{Ct})$ values were used to calculate mRNA levels relative to $18 \mathrm{~S}$ rRNA expression using the $2^{\wedge \wedge}(-\Delta \Delta C t)$ method.

\section{Sequencing strategy for patients' samples}

cDNA obtained from RNA of patients' PBMCs as described above was used to sequence the 3'UTR region of RRAS2. A nested PCR was performed for this purpose, using the oligonucleotide with sequence GCAGGA CAAGAAGAGTTTGGA, aligning to exon 3 of RRAS2 as FW, and oligonucleotide TGAAGCAGCCTTAGT GTTTCCTT, aligning to RRAS2 3'UTR as RV in the first PCR. For the nested PCR, the product of the first PCR was used as template and the utilized oligonucleotides were TCCATGAACTTGTCCGGGTT, aligning to exon 5 of RRAS2, as FW with the same RV oligonucleotide as in the first PCR. The product of this second PCR was sent to sequence by the Sanger method (Eurofins Genomics), using both FW and RV primers from the second PCR. Both PCR reactions were performed using 30 cycles of $45 \mathrm{~s}$ at $95^{\circ} \mathrm{C}, 45 \mathrm{~s}$ at $60^{\circ} \mathrm{C}$ and $2 \mathrm{~min}$ at $72^{\circ} \mathrm{C}$. All oligonucleotides are indicated in their $5^{\prime}-3^{\prime}$ orientation.

Alternatively, specific oligonucleotides were used to detect the presence of $\mathrm{C}$ or $\mathrm{G}$ allele by qPCR using the patients' cDNA as template. These oligonucleotides were designed as described in [27]. Their sequences can be provided upon request.

\section{RNA sequencing}

Library preparation and sequencing were carried out in 'Fundación Parque Científico de Madrid'. Briefly, Qiagen RNA Miniprep Kit was used for total RNA extraction following the manufacturer recommendations (including DNase treatment). Once extracted, $100 \mathrm{pg}$ of total RNA from each sample were used as input for library preparation with "NEBNext Single Cell/Low Input RNA Library Prep Kit for Illumina" (New England BioLabs) following the manufacturer recommendations. The so-obtained libraries were validated and quantified in a 2100 Bioanalyzer (Agilent) and an equimolecular pool was made, purified using AMPure XP beads (Beckman Coulter) and titrated by quantitative PCR using the "Kapa-SYBR FAST qPCR kit forLightCycler480" and a reference standard for quantification. The library pool was denatured and seeded on a NextSeq v2.5 flowcell (Illumina) where clusters were formed and sequenced using a "NextSeq 500 High Output kit v2.5" (Illumina) in a $1 \times 75$ single-read sequencing run on a NextSeq 500 sequencer (Illumina).

\section{BCR clonality assays}

CD19+ CD5+ IgM + cells were sorted from peripheral blood of Rosa26-RRAS2fl/flx mb1Cre mice using a FACSAria Fusion BSC II sorter and their gDNA was isolated using the QIAamp DNA Mini Kit from QIAGEN. Using this material as template, different PCRs were carried out to detect specific Vh family usage. In all cases, the oligonucleotide GTCTAGATTCTCACAAGAGTCCGATAG ACCCTGG aligning to the J3 region was used as reverse with specific oligonucleotides for each of the Vh families as forward. 7183: AAGAASAMCCTGTWCCTGCA ATGASC; J558: TCCARCACAGCCTWCATGCARCTC ARC; 3609: KCYYTGAAGAGCCRRCTCACAATCTCC; Vh11: GAAGTGCAGCTGTTGGAGACTGGAGAA; Vh12: ATCCGTCAGTCACCTGGGAAACCC. The sequences are presented $5^{\prime}$ to $3^{\prime}$. Degenerated nucleotides are coded as follows: $\mathrm{S}=\mathrm{C}$ or $\mathrm{G} ; \mathrm{M}=\mathrm{A}$ or $\mathrm{C} ; \mathrm{W}=\mathrm{A}$ or $\mathrm{T}$; $\mathrm{R}=\mathrm{A}$ or $\mathrm{G} ; \mathrm{K}=\mathrm{T}$ or $\mathrm{G} ; \mathrm{Y}=\mathrm{C}$ or $\mathrm{T}$. Oligonucleotides and PCR strategies were designed as described in $[28,29]$. 


\section{Statistical analysis}

Statistical parameters including the exact value of $n$, the mean $+/-$ S.D. or S.E.M. are described in the Figures and Figure legends. Non-parametric Wilcoxon-Mann-Whitney and parametric Student's $t$ and One-way ANOVA tests were used as indicated to assess the significance of mean differences. The number of mice to be used for comparison was calculated from preliminary experiments aimed to generate significant data using a twosided t-test with alpha $=0.05$ and a standard deviation of about 0.3 . The different deviation of the control and test (leukemic) groups suggested the use of different number of animals of each for the definitive experiments. All data was analyzed using the GraphPad Prism 7 software.

\section{Results}

RRAS2 is frequently overexpressed in human CLL and its overexpression in wild type form drives the development of leukemia

Approximately $13 \%$ of all human cancers have alterations in at least one of the classic RAS genes (cBioportal for cancer genomics, www.cbioportal.org). Of those, $K R A S$ is the most frequently altered, affecting $10 \%$ of patients. Although there are gene amplifications affecting the KRAS locus, most of the alterations detected consist of point mutations in the coding sequence (Fig. 1a). Mucinous adenocarcinomas of the appendix and pancreatic adenocarcinomas are the cancers with the highest frequency of missense mutations in KRAS, above $80 \%$ (Fig. 1a). In contrast, gene alterations affecting the RRAS2 locus have been found in less than $1 \%$ of all cancers and those alterations involve mostly gene amplifications (Fig. 1b). Squamous cell carcinomas of the oropharynx are the cancers with the highest rate of missense mutations that however barely reach $9 \%$ of the tumors (Fig. 1b). In contrast, RRAS2 is very frequently overexpressed in the wild type form in different types of cancer, being CLL followed by B-cell non-Hodgkin lymphomas the cancers with the highest expression of mRNA for RRAS2 (Fig. 1c; https://dcc.icgc.org/pcawg). In another previous study, CLL was found as the leukemia with the highest expression of $R R A S 2$, peaking at approximately 8-fold more mRNA than blood cells from healthy donors (Fig. S1a, www.oncomine.org [30]).

Given that the wild type form of RRAS2 has a potent transforming activity of NIH-3 T3 fibroblasts [10], we interrogated if overexpression of wild-type RRAS2 could cause CLL. To this end, we followed a genetic approach by generating a mouse line with a cassette containing the wild-type sequence of human RRAS2 under a CAG promoter in the Rosa26 locus, which includes EGFP after an IRES sequence and a LoxP-flanked stop codon (Rosa26-RRAS2 ${ }^{f l f l}$ ) at the $5^{\prime}$ end of the construct (Fig.
S1b). Crossing this mouse line with different Cre recombinase lines induces removal of the stop codon upon recombination and hence overexpression of R-RAS2 protein in specified tissues. We first set out to study systemic $R R A S 2$ overexpression using Sox2-Cre mice, where Sox 2 is an embryonic stem cell transcription factor and therefore will induce deletion of the LoxP-flanked sequence in all tissues. Rosa26-RRAS2 $2^{f l f l} \times \mathrm{xSox} 2-\mathrm{Cre}$ mice are viable and fertile in hetero- and homozygosity. In control WT mice, Rras 2 mRNA is highly expressed in lymphoid organs (spleen and lymph nodes) compared to other organs like kidneys, skin or liver (Fig. S1c). On top of that, expression of the combined RRAS2 + Rras 2 mRNA (human and mouse) in Rosa26-RRAS2 $2^{f l / f l} \mathrm{xSox2}$-Cre mice was found increased in the spleen, lymph nodes, liver, skin and kidneys (Fig. S1c). We did not find evident anomalies in those organs, except in the spleen. Rosa26$R R A S 2^{f l / f l} \mathrm{xSox} 2-C r e$ mice presented marked splenomegaly (Fig. 1d) that was also manifested in terms of organ weight; spleens of Rosa26-RRAS2 ${ }^{f l / f l} \mathrm{xSox} 2-\mathrm{Cre}$ mice were 3 -fold larger on average than spleens from control Rosa26-RRAS2 $2^{f / f l}$ littermates (Fig. S1d). Spleen enlargement was paralleled by a net increase in the number of CD19+ B cells, suggesting that splenomegaly was due to $B$ cell lymphocytosis (Fig. 1e). In addition, spleen size increased with age and was concomitant with enlarged follicles and loss of predominant diffuse red pulp areas, as observed by histopathological examination after hematoxylin and eosin staining (Fig. 1f).

The analysis by flow cytometry of marginal zone (MZ) and follicular B cell populations in 8-week-old mice showed the presence of an abnormal and abundant $\mathrm{CD} 19^{+} \mathrm{CD} 21^{-} \mathrm{CD} 23^{-}$population in Rosa26-RRAS2 $2^{f /}$ ${ }^{f} \mathrm{xSox} 2-\mathrm{Cre}$ mice, as well as an abundant $\operatorname{IgM}^{+} \operatorname{IgD}{ }^{-}$ population (Fig. 1g). Those populations of B cells could correspond to a transitional T1 population of $\mathrm{B}$ cells in their differentiation towards follicular or MZ B cells [31]. However, those cells expressed the CD5 marker, constituting a $\mathrm{CD} 19^{+} \mathrm{IgM}^{+} \mathrm{CD}^{+}$population which was abundantly detected in spleens of Rosa26-RRAS2 $2^{f l f l} \times$ Sox2-Cre mice but not in those of control Rosa26-RRAS2 $2^{f / f l}$ mice

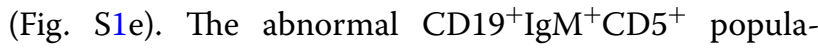
tion was also detected in the bone marrow (Fig. S1f) and was present in high number in the blood (Fig. 1h and i), suggesting that that the lymphoproliferative disease in Rosa26-RRAS2 $2^{f l f l} \times$ Sox2-Cre mice is indeed a B cell leukemia.

We next set out to determine if overexpression of human RRAS2 caused the generation of a $\mathrm{B}$ cell leukemia in a B cell-intrinsic manner. To this end, we crossed Rosa26-RRAS2 $2^{f l f l}$ mice with mb1-Cre mice which express Cre recombinase specifically in B cells starting at an early precursor phase [23]. Those mice accumulated a 
large number of $\mathrm{CD} 19^{+} \mathrm{IgM}^{+} \mathrm{CD} 5^{+} \mathrm{B}$ cells in the blood, showing that the development of the $\mathrm{B}$ cell leukemia is $\mathrm{B}$ cell-intrinsic (Fig. 2a and b).

The presence of increasingly large numbers of IgM + CD5 + B cells in the blood is a feature of human CLL [3]. We found that the number of leukemic $\mathrm{CD} 19^{+} \mathrm{IgM}^{+} \mathrm{CD} 5^{+} \mathrm{B}$ cells in the blood progressed with age in nearly all Rosa26-RRAS2 $2^{f l f l} \mathrm{xmb1-Cre} \mathrm{mice}$ (Fig. 2c). The time-dependent increase in leukemic cell numbers in the blood may be responsible for the reduced life span of Rosa26-RRAS2 ${ }^{\text {fl/fl}} \mathrm{xmb1-Cre} \mathrm{mice}$ (t1/2 $=13$ months) compared to that of wild type controls $(\mathrm{t} 1 / 2=32$ months, Fig. $2 \mathrm{~d})$. Another feature of some patients with CLL is the increased concentration of IgM in serum, something that was also detected in Rosa26$R R A S 2^{f l f l} \mathrm{xmb1-Cre} \mathrm{mice} \mathrm{(Fig.} \mathrm{S1g).} \mathrm{A} \mathrm{Giemsa} \mathrm{staining}$ of a blood smear showed the presence of enlarged lymphocytes with higher cytoplasmic content in Rosa26$R R A S 2^{f l f l} \mathrm{xmb1-Cre}$ mice than those of WT control mice (Fig. S1h). Along these lines, the analysis by flow cytometry of the Forward Scatter parameter showed that the CD19+CD5+ cells in blood are larger than normal (Fig. S1i and k). However, the analysis of cells entering the cell cycle in a period of $24 \mathrm{~h}$ by i.v. administration of the thymidine analogue BrdU showed that only $0.2 \%$ of the CD19+ CD5 + cells in the blood had incorporated BrdU (Fig. S1 $\mathrm{j}$ and $\mathrm{k}$ ), indicating that, in spite of being large, the CD19+CD5+ leukemic cells in blood are not progressing through the cell cycle and are not lymphoblastic. The low rate of proliferation in blood correlate with findings in human CLL suggesting that circulating leukemic B cells are not in proliferation [32].

To demonstrate that $R R A S 2^{f l / f} \mathrm{xmb1}$-Cre mice develop a CLL leukemia that can be transplanted to normal mice, we carried out adoptive transfer experiments in which sub-lethally irradiated wild-type mice expressing the hematopoietic cell allele marker CD45.1 were transferred with total B cells from young Rosa26-RRAS2 $2^{f l f l} \mathrm{xmb1-}$ Cre mice or Rosa26-RRAS2 $2^{f l f l}$ controls. Donor mice bear the CD45.2 allele and therefore transferred cells can be distinguished from endogenous ones according to the expression of the CD45.2 marker (Fig. 2e). We followed the progression of the leukemic $\mathrm{CD} 19^{+} \mathrm{IgM}^{+} \mathrm{CD} 5^{+} \mathrm{B}$ cell population in the blood of the transferred mice and observed a progressive increase over time of the percentage of leukemic cells within the total (donor plus acceptor) B cell population (Fig. 2f). Those experiments demonstrated that the abnormal $\mathrm{B}$ cell population (or its precursors) can be transplanted and expands in nondiseased recipient mice, adding further support to the notion that the $\mathrm{CD} 19^{+} \operatorname{IgM}^{+} \mathrm{CD} 5^{+} \mathrm{B}$ cell population is a CLL.

We also carried out an analysis of $\mathrm{V}_{\mathrm{H}}$ family usage in 9 independent Rosa26-RRAS2 $2^{f l f l} \mathrm{xmb1-Cre} \mathrm{mice} \mathrm{by} \mathrm{PCR} \mathrm{of}$ genomic DNA. We found that, unlike total bone marrow cells from a wild-type donor (BM, Fig. 2g), which did not result in amplification of any particular band (except for $\mathrm{V}_{\mathrm{H}}$ family J558), sorted $\mathrm{CD} 19^{+} \mathrm{IgM}^{+} \mathrm{CD}^{+} \mathrm{B}$ cells from mice with RRAS2 overexpression had overrepresentation of some $\mathrm{V}_{\mathrm{H}}$ families resulting in a pattern of bands that

\section{(See figure on next page.)}

Fig. 2 CD5 + IgM + B cells are oligoclonal and can be transferred to wild type mice. a Two-parameter flow cytometry of the expression of CD19 and CD5 in blood cells of 35 wk-old control and Rosa26-RRAS2 f/fl $x \mathrm{mb} 1$-Cre (mb1-Cre+) mice. b Quantification of the number of CD5 + IgM+ B cells (CD19+) in the blood of 30-35 wk-old control $(n=10)$ and mb1-Cre $(n=47)$ mice. Unpaired t-test with Welch's correction. $\mathbf{c}$ Dot plot representation of the quantification of $\mathrm{CD} 5+\lg \mathrm{M}+\mathrm{B}$ cells $(\mathrm{CD} 19+)$ in the blood of mb1-Cre mice $(n=14)$ and its evolution over time. Data points were adjusted to an exponential growth. d Kaplan-Meier survival plot of Rosa26-RRAS2f//f xmb1-Cre (mb1-Cre +$)$ mice $(n=22)$ and WT control C57BL/6 J mice $(n=40)$ allowed to age in the same housing conditions. Median survival for mb1-Cre $=13.57$ months; median survival for WT controls $=32.39$ months. $P<0.0001$, long-rank Mantel-Cox test and Gehan-Breslow-Wilcoxon test. e Experimental setup for the adoptive transfer experiment. Total B cells from mouse donors bearing the hematopoietic cell marker allele CD45.2 were purified and inoculated i.v. in the tail vein of sublethaly irradiated wild type recipient of the same strain (C57BL/6) but bearing the CD45.1 allele. Donor control mice refer to Rosa26-RRAS2 ${ }^{f / f l}$ without Cre recombinase 11 wk-old and the donor problem mice corresponded to 16 wk-old Rosa26-RRAS2 $2^{\text {flf }} \times$ mb1-Cre. f Quantification by flow cytometry of the expression of CD45.2 and CD5 within the CD19+ population of inoculated CD45.1+ mice $(n=8)$ and bled at the indicated time points. In this figure, control mice refer to Rosa26-RRAS2 $2^{\mathrm{f} / \mathrm{fl}}$ without Cre recombinase. Two-way ANOVA test. $\mathbf{g}$ PCR results of using specific forward oligonucleotides for different $V_{H}$ families and a constant reverse oligonucleotide against the $\mathrm{J}$ region of the immunoglobulin heavy chain gene. The specific $\mathrm{V}_{H}$ families analyzed in each case are indicated on top of each section of the agarose gel. $\mathrm{H}_{2} \mathrm{O}$ is used as a negative control. In each $\mathrm{V}_{H}$ family, BM corresponds to bone marrow cells of a wild-type 12 wk-old mouse, T corresponds to sorted naïve thymocytes (no recombination) from a wild type 6 wk-old mouse, and each column corresponds to the spleen of an individual mb1-Cre mouse of ages between 35 and 40 weeks. $\mathbf{h}$

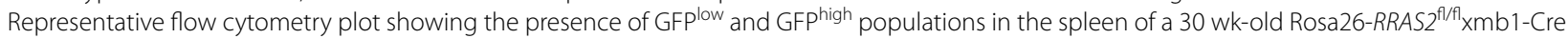
mouse. i RT-qPCR for the differentially expressed RRAS2 gene in the CD19+CD5+ GFPhigh and GFPlow populations sorted from spleens of $n=7$ 30-35 wk-old Rosa26-RRAS2 ${ }^{f / f} \mathrm{xmb1-Cre} \mathrm{mice} \mathrm{compared} \mathrm{to} \mathrm{follicular} \mathrm{B} \mathrm{cells} \mathrm{of} n=630$ wk-old WT mouse controls. One-way ANOVA test. $\mathbf{j}$ Dot plot representation of GFPhigh CD5+ leukemic B cell evolution in blood from mb1-Cre mice over time, showing each mouse individually ( $n=14)$. Data points were adjusted to a linear fit. $\mathbf{k}$ Paraffin-embedded lung tissue section stained with hematoxylin-eosin, showing representative lymphocytic infiltration in one out of three $35 \mathrm{wk}$-old Rosa26-RRAS2 $2^{\mathrm{f} / \mathrm{fl}} \mathrm{xmb1-Cre} \mathrm{mice.} \mathrm{I} \mathrm{Percentage} \mathrm{of} \mathrm{IgM} \mathrm{+} \mathrm{CD5} \mathrm{+} \mathrm{B} \mathrm{cells} \mathrm{within} \mathrm{the} \mathrm{lymphoid} \mathrm{population}$ infiltrating the lungs of $n=235$ wk-old Rosa26-RRAS2 $\mathrm{f}^{\mathrm{f} / \mathrm{f}} \mathrm{xmb} 1$-Cre mice compared to $n=232 \mathrm{wk}$-old Rosa26-RRAS2 ${ }^{\mathrm{fl} / \mathrm{f}}$ control ones. $\mathbf{m}$ Bar plot of the distribution of lymphoid cells between the GFPlow and GFPhigh populations in the lungs and lymph nodes (LN) of 20 wk-old Rosa26-RRAS2 ${ }^{\text {fl/ }}$ flxmb1-Cre mice $(n=2)$ 


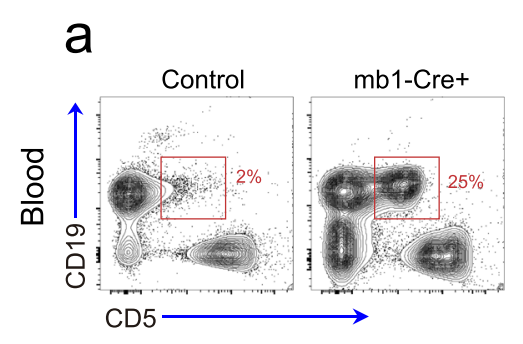

d Kaplan-Meier Survival plot

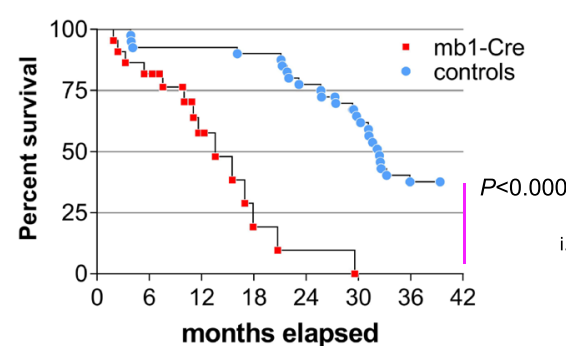

9 VH oligoclonality
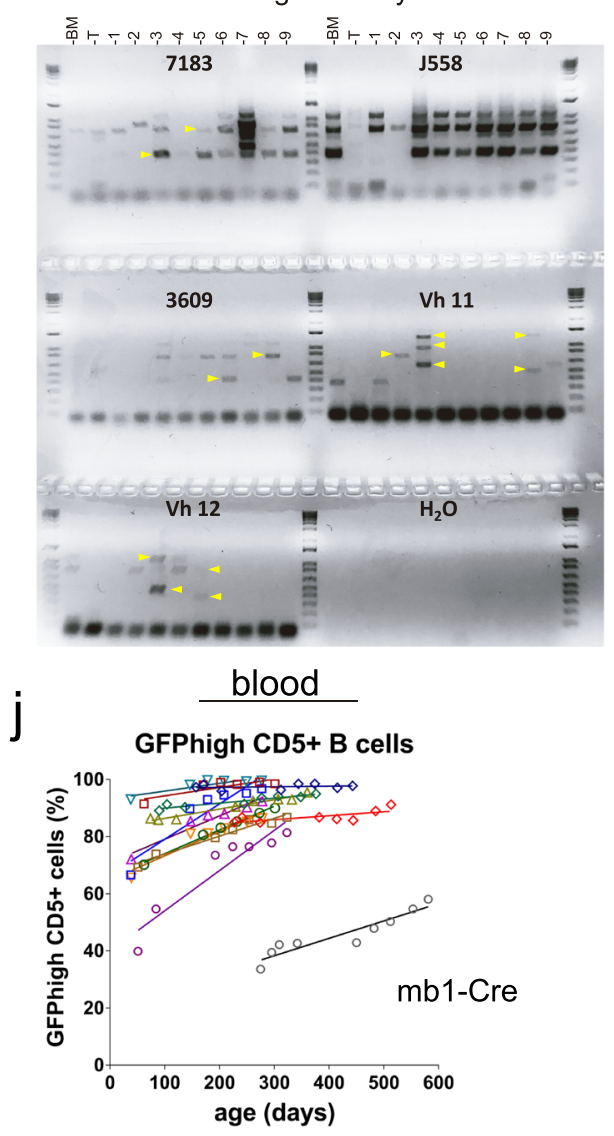

b

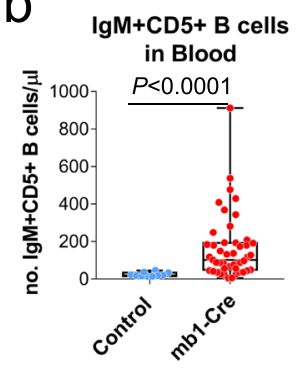

C Age-dependent evolution of IgM+ CD5+ B cells in blood

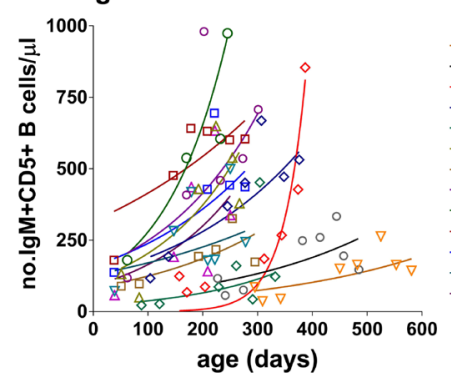

7 mouse 11 - mouse 37
mouse 43 $\rightarrow$ mouse 52 \# mouse 58 $\triangle$ mouse 64 * mouse 68 - mouse 76

F mouse 81

mouse 83 7 mouse 84 $\triangle$ mouse 85

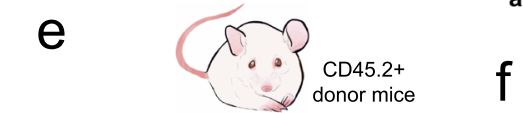

R26-RRAS2ff/fl (control) or $R$ 26-RRAS2fl/fI $x$ mb1-Cre (mb1-Cre)

i.v.inoculation sorted $\mathrm{CD} 45.2+\mathrm{CD} 19+$ Bcells<smiles>CC1CC2CC3CCCC(C2)C(C1)C3</smiles>
WT CD45.1+ recipient mice $>$ periodic
$\Rightarrow$ bleedings

h mb1-Cre

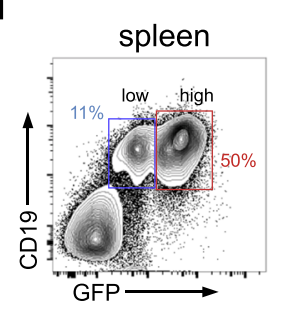

k

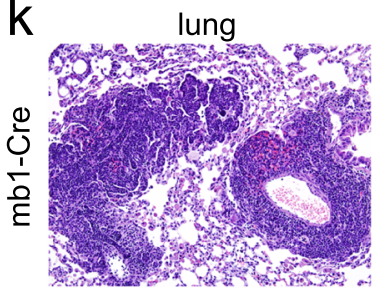

$\mathrm{m}$ Distribution of GFP populations

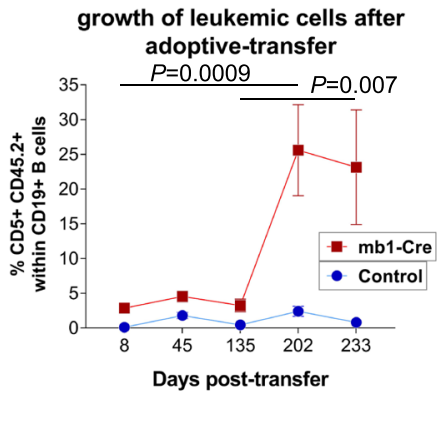
adoptive-transfer
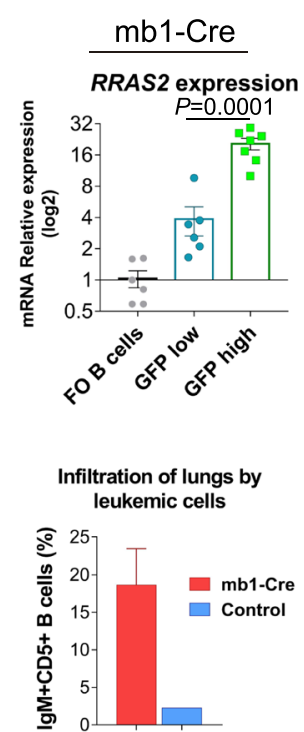
within infiltrating cells

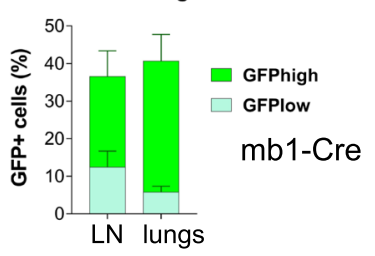

Fig. 2 (See legend on previous page.) 
was specific to each individual mouse. Those data indicate that $\mathrm{CD} 19^{+} \mathrm{IgM}^{+} \mathrm{CD} 5^{+} \mathrm{B}$ cells are oligoclonal and, therefore, additionally support the notion that RRAS2overexpressing mice develop a CLL leukemia. Interestingly, the oligoclonal $\mathrm{BCR}$ repertoire in the analyzed mice included families known to mediate autoimmunity, i.e., VH11 and VH12 [33, 34]. Autoantigens have been shown to select $\mathrm{B}$ cells with exacerbated $\mathrm{BCR}$ signaling, hence inducing aggressive progression of CLL mouse models [35].

The expression of markers, the oligoclonality, the transferability, the slow steady increase of non-blastic, nonmitotic, B cells in the blood are all features of human CLL. Therefore, the results presented in Figs. 1 and 2 demonstrate that overexpression of human RRAS2 provokes the development of a CLL in mice, suggesting a cause-effect relationship for RRAS2 overexpression in the human disease.

\section{Time-dependent increase of RRAS2 expression in leukemic $B$ cells}

Taking advantage of the GFP marker included in the RRAS2 overexpression cassette in the Rosa26 locus (Fig. S1b), we could track cells in the blood and lymphoid organs of Rosa26-RRAS2xSox2-Cre and Rosa26-RRAS2xmb1-Cre mice. Interestingly, in Rosa26RRAS2xmb1-Cre mice, two distinct populations of $\mathrm{CD} 19^{+} \mathrm{B}$ cells with approximately a 10-fold difference in GFP expression were detected in blood: a GFP low and a GFP ${ }^{\text {high }}$ population (Fig. 2h). Likewise, the two populations of GFP ${ }^{\text {low }}$ and a GFP ${ }^{\text {high }} \mathrm{B}$ cells were also identified in the lymphoid organs of Rosa26-RRAS2xSox2-Cre mice (Fig. S2a). By contrast, T cells from those mice had a predominant $\mathrm{GFP}^{\text {low }}$ population. Interestingly, the presence of the GFP ${ }^{\text {high }}$ population was more abundant within the leukemic $\mathrm{CD}^{+}$cell pool than within the follicular CD23 ${ }^{+}$B cell population (Fig. S2b). In the leukemic, $\mathrm{CD}^{+} \mathrm{B}$ cells, $80 \%$ were GFP high. Those results suggested that the enrichment in GFP ${ }^{\text {high }}$ cells was taking place only within the leukemic B cell population.

To study this phenomenon, we first determined if the levels of GFP expression were correlated with those of RRAS2 expression. We sorted each of the GFP populations from total $\mathrm{CD}_{1} 9^{+} \mathrm{CD}^{+}$cells from Rosa26RRAS2xmb1-Cre mouse spleens and measured RRAS2 mRNA expression by RT-qPCR. We found that RRAS2 was overexpressed in the GFP ${ }^{\text {low }}$ population by 3.8 -fold in comparison with follicular B cells from wild-type mice, whereas overexpression reached a mean of 20-fold in the GFP $^{\text {high }}$ population (Fig. 2i). A Western blot analysis of whole cell lysates of sorted GFP ${ }^{\text {low }}$ and $\mathrm{GFP}^{\text {high }}$ leukemic cells showed that R-RAS2 protein expression was also much higher in GFP high than in GFP ${ }^{\text {low }}$ cells (Fig. S2c).
Therefore, RRAS2 in CD5+ B cells is overexpressed in two populations, one with moderate and the other with very high (20-fold) levels. Interestingly, we found that the GFP ${ }^{\text {high }} / \mathrm{GFP}^{\text {low }}$ proportion within the $\mathrm{CD} 19^{+} \mathrm{CD} 5^{+}$ $B$ cell population in the blood increases with age when mice are analyzed individually by periodic bleedings (Fig. 2j and Fig. S2d). In some mice, we detected infiltration of non-hematopoietic tissues such as kidneys, lungs and liver by lymphoid cells in old Rosa26-RRAS2xmb1Cre mice. For instance, in 3 out of 17 one-year-old males, we detected perivascular infiltration of the lungs by lymphoid cells that were not forming follicles (Fig. 2k). The analysis by flow cytometry indicated that those infiltrates were constituted mainly by $\mathrm{CD} 19^{+} \mathrm{CD}^{+}$leukemic $\mathrm{B}$ cells (Fig. 2l) with an overrepresentation of GFP ${ }^{\text {high }}$ cells (Fig. 2m). These data suggest that $\mathrm{CD} 19^{+} \mathrm{CD} 5^{+} \mathrm{B}$ cells with the highest expression of RRAS2 are the ones with the highest metastatic potential. Those data suggest that the age-dependent enrichment in $\mathrm{CD} 19^{+} \mathrm{CD} 5^{+} \mathrm{B}$ cells with the highest expression of GFP is the result of a selective pressure that favors cells with the highest expression of RRAS2 and metastatic potential. Furthermore, the analysis of B cell markers in GFP high and GFP ${ }^{\text {low }}$ cells in spleen shows that GFP ${ }^{\text {high }}$ are the cells with the highest proportion of CD21-CD23-CD19+ B cells (53\%, Fig. S2e) and downregulated IgD, CD21, and B220. Interestingly, B220 downregulation is typical of B1 CD5+ B cells which are suspected to be the origin of leukemic cells in an E $\mu$-TLC1 mouse model of CLL [36]. In an attempt to determine if CD19+CD5+ leukemic B cells in Rosa26RRAS2xmb1-Cre mice derive from $\mathrm{B} 1 \mathrm{CD} 5+$ cells, we quantified the number of $B$ cells in the peritoneum, a site rich in B1a and B1b cells, according to the expression of the CD11b and CD5+ markers. We found that leukemic cells were $\mathrm{CD} 11 \mathrm{~b}+\mathrm{CD} 5+$, markers of B1a cells (Fig. S3a). However, although the number of B cells with those markers was increased 7-fold compared to WT controls, the number of cells with the same markers was increased by 10 -fold in spleen. Therefore, it is not possible to assign a B1a origin in the peritoneum or the spleen according to cell numbers. IgM expression was more heterogeneous in the leukemic CD11b + CD5+ population of the peritoneum than in B1a cells of control WT mice (Fig. S3b). On the other hand, B220 was low or negative in both peritoneal WT B1a cells and leukemic cells (Fig. S3c). This population was enriched in the spleen of leukemic mice compared to WT controls. B1 cells emerge early in life from precursors in the liver. We compared the number of CD19+CD5+ cells and the expression of different markers in 2 week-old mice of Rosa26-RRAS2xmb1-Cre mice with age-matched controls. We found that the liver of leukemic mice was enriched in CD19+CD5+ negative for B220, CD21, CD23 and expressing intermediate levels 
of CD24 and high levels of CD38 (Fig. S4). However, the same phenotype and even bigger number of cells were already present in the spleen. Therefore, we cannot conclude if leukemic CD19+CD5+ in RRAS2-overexpressing mice have a B1a origin in the liver or if they develop from mature $B$ cells in the spleen.

To further compare the GFP low and GFP $\mathrm{P}^{\text {high }} \mathrm{B}$ cell populations, and these with leukemic CD19+CD5+ B cells and normal follicular B cells, we carried out an RNAseq analysis of the transcriptome. We compared the following cell populations: follicular B cells sorted from spleens of six wild-type C57BL/6 mice; sorted CD19+CD5+ leukemic $B$ cells from spleens of six independent Rosa26RRAS2xmb1-Cre mice; sorted normal B follicular B cells from the spleens of two Rosa26-RRAS2xmb1-Cre mice; sorted $\mathrm{CD} 19+\mathrm{GFP}^{\text {low }}$ and sorted $\mathrm{CD} 19+\mathrm{GFP}^{\text {high }} \mathrm{B}$ cell populations from two Rosa26-RRAS2xmb1-Cre mice. Gene expression data is summarized in Table S1. Principal component analysis shows a clustering of follicular B cells from Rosa26-RRAS2xmb1-Cre mice together with follicular B cells from wild-type C57BL/6 mice and of $\mathrm{GFP}^{\text {low }}$ and $\mathrm{GFP}^{\text {high }} \mathrm{B}$ cell populations with leukemic $B$ cells (Fig. S5a). A comparison of the most differentially expressed genes in GFP ${ }^{\text {low }}$ versus GFP high $B$ cell populations with their expression in leukemic (CD19+CD5+) and normal follicular $B$ cells populations shows that $\mathrm{GFP}^{\text {high }} \mathrm{B}$ cells are more closely related to leukemic cells than GFP ${ }^{\text {low }}$ B cells (Fig. S2f).

\section{Overexpression of wild-type R-RAS2, but not expression of an oncogenic mutant of R-RAS2, induces CLL}

Unlike for $K R A S$, oncogenic mutations in RRAS2 are rarely found in human cancer (Fig. 1a and b). However, the oncogenic mutation Q72L in RRAS2 has been found as a hotspot [37]. Indeed, of the 218 cancer samples (out of 45,604) with gene alterations in RRAS2, the missense mutation Q72L was the most frequent (www.cbioportal. org and Fig. S6a). To determine if mice expressing the Q72L mutant of Rras2 also developed CLL, we crossed knock-in $\operatorname{Rras} 2(\mathrm{Q} 72 \mathrm{~L})^{\mathrm{fl} / \mathrm{fl}}$ mice bearing a repeated and inverted exon 3 in the Rras 2 locus with mb1-Cre mice to specifically exchange wild-type exon 3 for the mutant exon in B cells. The transcription of the Rras2 locus bearing the Q72L mutation was equivalent to that of B cells from WT control mice and much lower than that of $\mathrm{B}$ cells from Rosa26-RRAS2xmb1-Cre mice (Fig. S6b). We analyzed 14-month-old mice and their control littermates (negative for mb1-Cre) for evidences of a CLL and found that the number of $\mathrm{B}$ cells in spleen and blood (Fig. S6c), the presence of CD19+CD5+ cells in blood (Fig. S6d), and the distribution of B cells among follicular, marginal zone and $\mathrm{CD} 21^{-} \mathrm{CD} 23^{-} \mathrm{B}$ cells (Fig. S6e) were within normal limits. These data suggested that overexpression of wild-type RRAS2 and not an oncogenic mutation drives the development of CLL in mice.

\section{A highly conserved pattern of somatic mutations accompanies the development of RRAS2-driven CLL}

The comparison of the transcriptome of six wild-type follicular B cell samples and seven independent leukemic samples using the Ingenuity Pathway Analysis (IPA) software revealed a strong signature of pathway alterations related to molecular mechanisms of cancer (Fig. S5b), thus confirming the malignant nature of the CD19+ CD5+ B cells expanding in Rosa26-RRAS2xmb1Cre mice. In addition, there is a signature of increased mTOR activity which could be expected given the capacity of R-RAS2 to activate this pathway in B cells (Fig. S7, and [14].

Nonetheless, the most striking finding resulting from the analysis of RNAseq data was that CD19+CD5+ leukemic cells from the spleens of seven independent mice showed the consistent presence of somatic mutations in 270 genes in all mice. Those mutations corresponded mostly to missense mutations and less so to frameshifts or nonsense mutations (Table S2). The mutated genes concentrated on chromosomes 7 and 4, followed by chromosomes 8, 9 and 17 (Fig. 3a). Chromosomes 2, 6, 12, 14, 16, 18 and both sex chromosomes contained no mutations in mRNA-encoding genes. IPA analysis of the 270 mutated genes identified a signature of genes related to immunological and hematological neoplasia (Fig. 3b) and

\section{(See figure on next page.)}

Fig. 3 RRAS2-driven CLL harbors a highly conserved pattern of somatic mutations. a Pie chart representation of the somatic mutation distribution

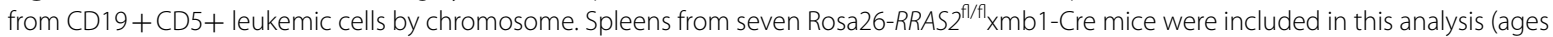
in panel e). b Ingenuity Pathway Analysis (IPA) diagram of the immunological and hematological neoplastic signature generated from the 270 mutations present in all seven different Rosa26-RRAS2 ${ }^{f / f} \times x_{1}$ b1-Cre mice. $\mathbf{c}$ Pie chart representation of the co-occurrence of gene mutations in murine CLL vs human CLL. d Summary of most frequently mutated genes in 1094 cases of human CLL also identified in Rosa26-RRAS2 murine CLL. The panel also shows each gene's condition in MBL (monoclonal B lymphocytosis) and other human leukemias (BL:Burkitt Lymphoma; MCL: Mantle Cell Lymphoma; DLBCL: Diffuse Large B Cell Lymphoma; CTL:Cutaneous T cell lymphoma; FL: Follicular Lymphoma; MM: Multiple Myeloma; MZL; Marginal Zone Lymphoma; SS: Sezary Syndrome). e Heatmap of mutation rates of 107 mutated genes detected in CD19+ CD5+ leukemic cells from seven Rosa26-RRAS2 $2^{\mathrm{f} / \mathrm{fl}} \mathrm{xmb1-Cre} \mathrm{independent} \mathrm{mice} \mathrm{(age} \mathrm{of} \mathrm{mice:} \mathrm{Ctrl} \mathrm{1-3,} 12$ wk.; Ctrl 4-6 25 wk.; BCLL-9, 104 wk.; BCLL10-11 and BCLL16-17, 54 wk.; BCLL13-14, 32 wk). Black: homozygous; grey: heterozygous; white: unmutated. f Schematic representation of registered missense mutations in SPEN, ARIDIA and AKAP13 in human CLL patients (green dots: missense mutation; black dots: truncating mutations; orange dots: splicing site mutation). Red text indicates mutations found in Rosa26-RRAS2 $2^{\mathrm{f} / \mathrm{f}} \mathrm{xmb} 1-\mathrm{Cre}$ mice which are also present in human genes 
a distribution of somatic mutations by murine chromosome

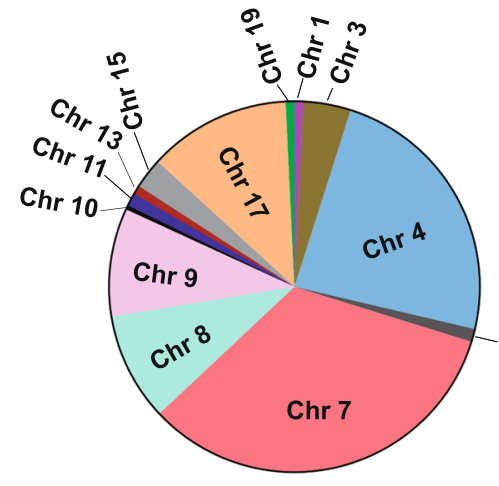

C

co-ocurrence of gene mutations in murine vs human $\mathrm{B}-\mathrm{CLL}$

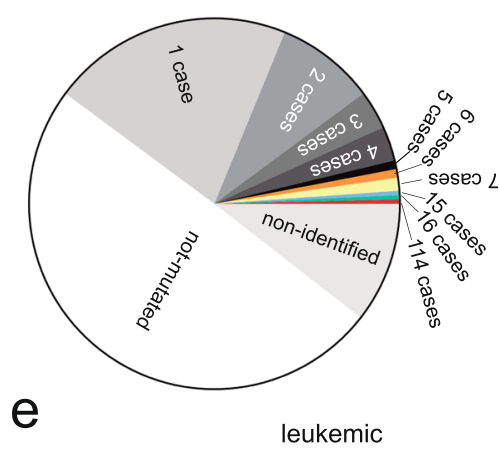

follicular B cells $\operatorname{lgM}+\mathrm{CD} 5+\mathrm{B}$ cells

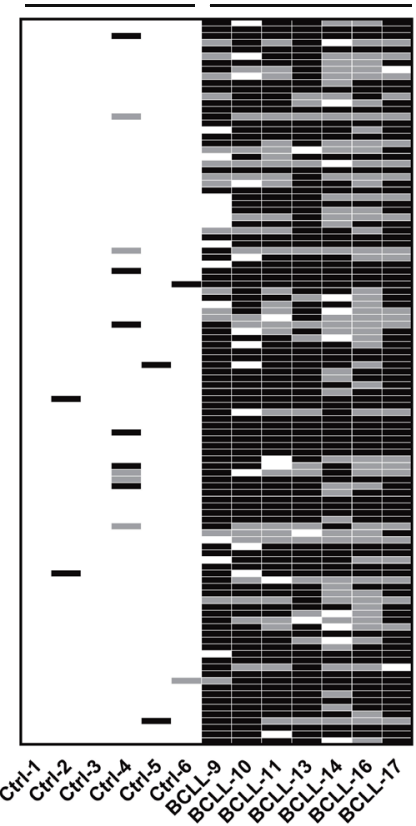

b cancer immunological/hematological disease

Chr 5

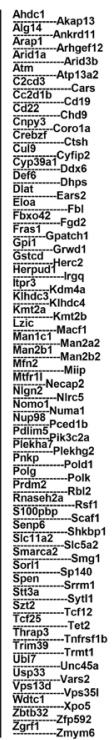

d

most frequently mutated genes in human B-CLL identified in R26-RRAS2 murine B-CLL

\begin{tabular}{|c|c|c|c|c|c|c|}
\hline $\begin{array}{l}\text { Gene } \\
\text { symbol }\end{array}$ & $\begin{array}{c}\text { Mutated in } \\
\text { Human } \\
\text { B-CCL }\end{array}$ & \begin{tabular}{|l} 
Cases \\
out of \\
1094
\end{tabular} & $\begin{array}{l}\text { Mutated in } \\
\text { Human MBL }\end{array}$ & \begin{tabular}{|c|} 
Cases \\
out of \\
54
\end{tabular} & $\begin{array}{l}\text { Mutated in other } \\
\text { Human leukemias }\end{array}$ & Mutations found in mouse R26-RRAS2 CLL \\
\hline Atm & $10.42 \%$ & 114 & $5.56 \%$ & 3 & $\begin{array}{l}\text { BL; MCL; DLBCL; CTL; } \\
\text { FL:MM }\end{array}$ & 12305L \\
\hline Arid1a & $1.46 \%$ & 16 & & & BL; MCL; DLBCL; MZL; & $\mathrm{S} 262 \mathrm{X} ; \Delta \mathrm{S} 262 ; \mathrm{N} 1804 \mathrm{~S} ; \mathrm{Y} 1760 \mathrm{~S} ; \mathrm{S} 129 \mathrm{G}$ \\
\hline Spen & $1.37 \%$ & 15 & & & DLBCL; MZLL MCL; SS; & $\begin{array}{l}\text { A3396T; L3008P; N2066S; V1660l; M16041; } \\
\text { S1582P:G1575R; T931A }\end{array}$ \\
\hline $\begin{array}{l}\text { Herc2 } \\
\text { Macf1 }\end{array}$ & $\begin{array}{l}0.64 \% \\
0.64 \%\end{array}$ & $\frac{7}{7}$ & & & BL; MCL; DLBCL; FL; & $\begin{array}{c}\text { G1235D } \\
\text { V3829A } \\
\end{array}$ \\
\hline Akap13 & $0.55 \%$ & 6 & $1.5 \%$ & 1 & MLIM; $M L L ;$ IL & $\begin{array}{l}\text { S357L; G644S; A776G; V904G; K1084R; } \\
\end{array}$ \\
\hline Tet2 & $0.55 \%$ & 6 & & & $\begin{array}{l}\mathrm{BL} ; \mathrm{MCL} ; \mathrm{DLBCL} ; \mathrm{FL} ; \\
\mathrm{MM}: \mathrm{MZL}\end{array}$ & 109N; N1102S; R195; ; P P12135; Q1468K \\
\hline$c d 22$ & $0.46 \%$ & 5 & & & DLBCL; MM & S829T; T807A; R250H; \\
\hline$\frac{P r d m 2}{A n k d 11}$ & $0.46 \%$ & $\frac{5}{4}$ & & & & $\begin{array}{c}\text { A333T } \\
\text { D13965 }\end{array}$ \\
\hline $\begin{array}{l}\text { Ankrant } \\
\text { Fras1 }\end{array}$ & $0.37 \%$ & $\frac{4}{4}$ & & & MCL; DLBCL & $\frac{1396 \mathrm{E}}{\mathrm{L} 3135 \mathrm{P}}$ \\
\hline$\frac{P i k 3 c 2 a}{P i k c a}$ & $0.37 \%$ & 4 & & & BL; MCL; DLBCL; FL; & K28R \\
\hline Rsf1 & $0.37 \%$ & 4 & & & & L539P \\
\hline & & 4 & & & & \\
\hline$S p 140$ & $0.37 \%$ & $\begin{array}{ll}4 \\
4\end{array}$ & & & MM; DLBCL; MCL; FL & $\frac{s 101}{V 481: F 143 S}$ \\
\hline $\begin{array}{l}\text { X } \text { Po5 } \\
\text { BL: Burkitt } \\
\text { MCL: Mantl } \\
\text { DLBCL: Diff } \\
\text { CTL: Cutan }\end{array}$ & $\begin{array}{l}0.37 \% \\
\text { homa } \\
\text { I Lymphor }\end{array}$ & & & & $\begin{array}{l}\text { FL: Follicular Lymphoma } \\
\text { MM: Multiple Myeloma } \\
\text { MZL: Marginal Zone Lymp } \\
\text { SS: Sezary Syndrome }\end{array}$ & \\
\hline
\end{tabular}

Frequency mutated allele

$$
\square 0
$$

$50 \%$

- $100 \%$
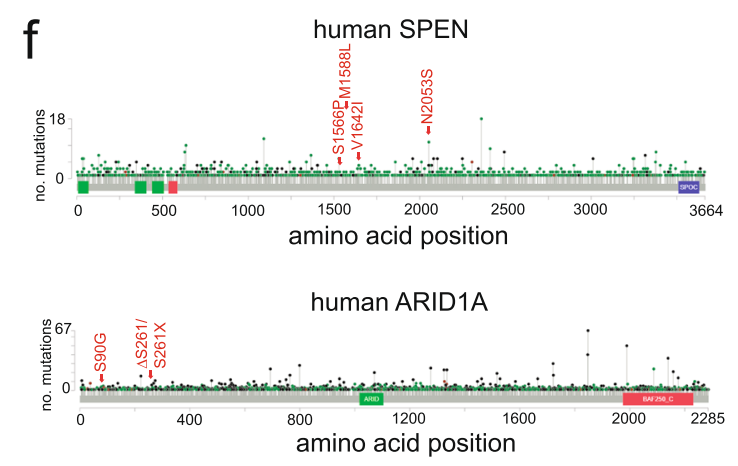

human AKAP13

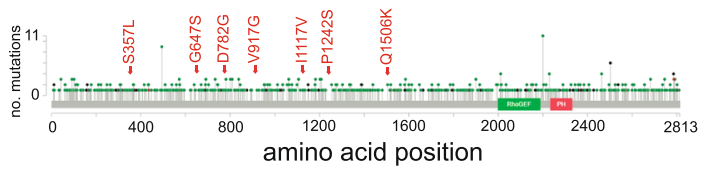

Fig. 3 (See legend on previous page.) 
to immunological development (Fig. S7); including genes such as Atm, Kmt2a, Macf1, Tet2, Akap13, Cd19, Cd22 and Polk. Finally, mutations in genes associated with retinoblastoma, cyclins and Atm, suggest that leukemic cells have unlocked the G1-S checkpoint (Fig. S7).

Out of the 270 genes found mutated in our RNAseq analysis of murine CLL cells, a total of 107 were found mutated within a cohort of 1094 human CLL patients and 8 within a cohort of 54 human MBL patients (www. cbioportal.org). Of those, the most frequently mutated gene in human CLL that is also found in our murine CLL model is ATM, with 114 cases out of 1094 patients (Fig. 3c). A table with the list of genes identified in four or more human CLL patients shows that, in addition to $A T M$, other known tumors suppressors such as ARID1A, AKAP13, PRDM2, SPEN, SMARCA2 and TET2 are also mutated (Fig. 3D). Within this set of genes, there are the epigenetic regulators ARID1A and SMARCA2, which form part of the chromatin remodeling complex, SWI/SNF, and the DNA damage repair genes ATM and HERC2. Most of the genes mutated in Rosa26-RRAS2 CLL leukemias and human CLL leukemias are also found mutated in other hematological cancers of $B$ and $T$ cells (Fig. 3d). A striking observation of our RNAseq analysis is that the vast majority of the 107 genes mutated in R26RRAS2 CLL, that are also found mutated in human CLL, were mutated in homozygosity (100\% of the sequences) or heterozygosity (50\% of the sequences) in leukemic cells from each of the seven independent mice (Fig. 3e). Those data suggest a strong selective pressure for a combination of accompanying gene mutations that drive CLL development in mice that overexpress wild-type $R R A S 2$, thus reinforcing the idea previously established that $\mathrm{B}$ cells with the highest RRAS2 expression $\left(\mathrm{GFP}^{\text {high }}\right.$, Fig. 2 and Fig. S2) are selected during evolution of the leukemia. Another piece of evidence supporting the idea of selection is that many genes contain multiple missense mutations in their mRNAs in $50 \%$ or even $100 \%$ of the sequences, suggesting an evolution of $\mathrm{B}$ cells with a progressive number of mutations in the same genes. An example is shown for the genes Spen, Arid1a and Akap13 that have multiple mutations in their coding sequences (Fig. 3f and Table S2). Those positions are also found mutated in human CLL.

\section{R-RAS2 is complexed with the BCR in leukemic cells and is required for proliferation and formation of tumors in xenografts by human CLL}

Human CLL is characterized by the presence of recurrent "stereotyped" BCRs often with similar or identical sequences in the IgHV chain $[6,38]$. This indicates that BCR signaling is fundamental for the development of CLL with the existence of stereotyped BCRs, suggesting the existence of common antigens (probably autoantigens) as initial triggers of the expansion of leukemic clones. Indeed, expression of the CD5 marker, characteristic of CLL, is induced by BCR signaling [39]. Our IgHV usage data (Fig. $2 \mathrm{~g}$ ) shows oligoclonality in the BCR repertoire of CLL cells emerging in Rosa26-RRAS2xmb1Cre mice. In addition, IPA analysis of gene transcription in leukemic versus normal follicular B cells (Table S1) shows a strong signature of active BCR signaling (Fig. 4a), suggesting that the $\mathrm{BCR}$ is actively signaling in leukemic cells with activation of the PI3K-Akt-mTOR, the NFKB and the NFAT pathways, among others.

We previously demonstrated that R-RAS2 is constitutively associated to both the BCR and the TCR of normal $\mathrm{B}$ and $\mathrm{T}$ cells, respectively [12], and that it is an activator of PI3K and mTOR pathways [12, 14]. Therefore, we investigated if R-RAS2 is also physically

\footnotetext{
(See figure on next page.)

Fig. 4 R-RAS2 is associated with the BCR in leukemic cells and is required for human CLL cell proliferation. a Ingenuity Pathway Analysis (IPA) of differentially expressed genes in leukemic versus normal follicular B cells. Pink-filled symbols: upregulated genes. Green-filled: downregulated genes. Double circle: protein complex; horizontal ellipse: transcription regulator; vertical ellipse: transmembrane receptor, diamond: enzyme; trapezium: transporter; triangle: phosphatase; inverted triangle: kinase; circle: other. Relationship labels: A: activation; B: binding; C: causation; CO: correlation; E: expression; EC: enzyme catalysis; I: inhibition; L: molecular cleavage; LO: localization; M: biochemical modification; miT: microRNA Targeting; P: phosphorylation/dephosphorylation; PD: protein-DNA binding; PP: protein-protein binding; PR: protein-RNA binding, RB: regulation of binding; RE: reaction; T: transcription; TR: translocation; UB: ubiquitination. b Western Blot of two-dimensional (2D) gel electrophoresis under non-reducing/reducing conditions of purified CD19+CD5+ cells from the spleen of a 45 wk-old Rosa26-RRAS2 ${ }^{\text {fl/fl } x m b 1-C r e ~ m o u s e . ~ L e f t: ~}$ co-immunoprecipitation of R-RAS2-interacting components using an anti-HA antibody. Right: isotype IgG2b control. Membranes were serially incubated with streptavidin-PO, anti-lgM and anti-HA. The positions of molecular weight markers are indicated to the left of each membrane. The blue line represents the mobility of proteins without inter-chain disulfide bridges. $\mathbf{c}$ Schematic representation of R-RAS2 interaction with the B-cell receptor and its downstream effects on canonical BCR signaling and the PI3K-Akt-mTOR pathway. $\mathbf{d}$ RT-qPCR analysis of RRAS2 expression in MEC-1 cell line transduced with scrambled control lentiviral particles (blue), shRNA for human RRAS2 (red), and expression of RRAS2 in healthy peripheral blood lymphocytes (grey). One-way ANOVA test. e In vitro proliferation assay of RRAS2 knockdown MEC-1 cells (red) and control (blue). Data show means \pm SEM from three biological replicates. Two-way ANOVA test, row factor. f Tumor growth in immunodeficient mice. $10 \times 10^{6}$ transduced MEC-1 cells per animal were subcutaneously injected. Data show means \pm SEM from a total of eight mice. Two-way ANOVA test, row factor. g \& h Flow cytometry analysis of Raf-ERK pathway and proximal BCR signaling components ERK (T202/Y204), VAV (Y174), BTK (Y223) and BLNK (Y96) phosphorylation in MEC-1 cell line transduced with scrambled control lentiviral particles (blue), shRNA for human RRAS2 (red) and treated with Src-kinases inhibitor PP2 $20 \mu \mathrm{M}$, Btk inhibitor Ibrutinib $10 \mu \mathrm{M}$ and MEK inhibitor U0126 $10 \mu \mathrm{M}$
} 
Hortal et al. Molecular Cancer

(2022) 21:35

Page 14 of 24

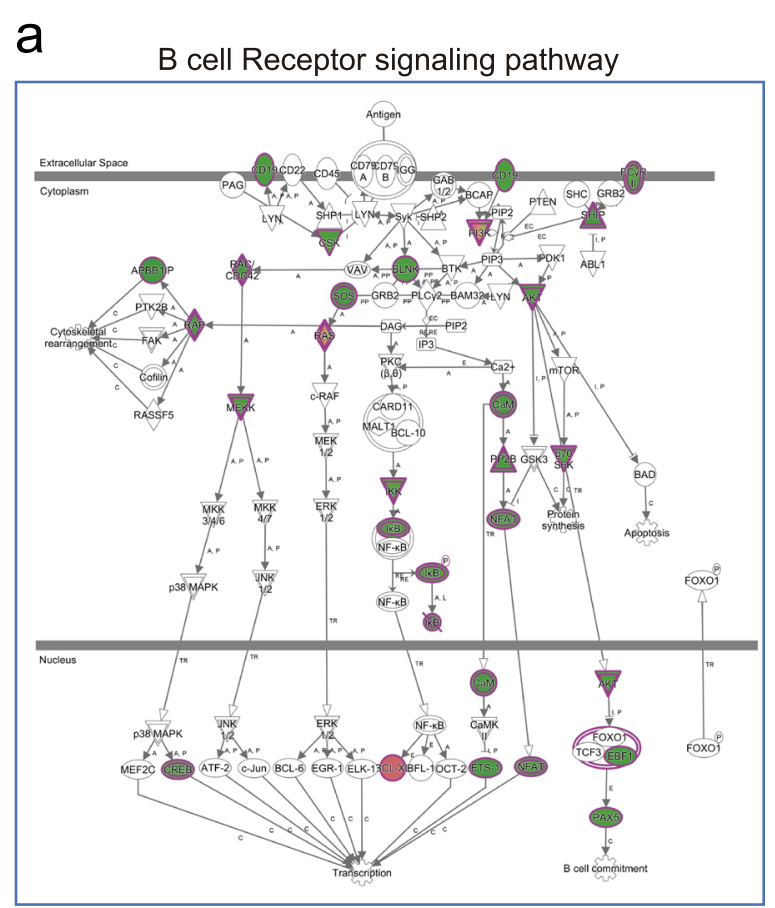

d
Human RRAS2 expression $P<0.0001$ b
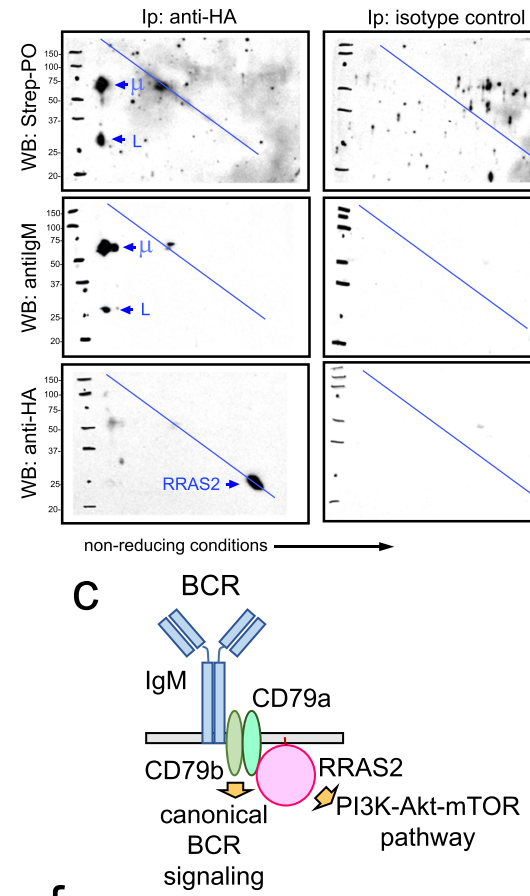

non-reducing conditions

C

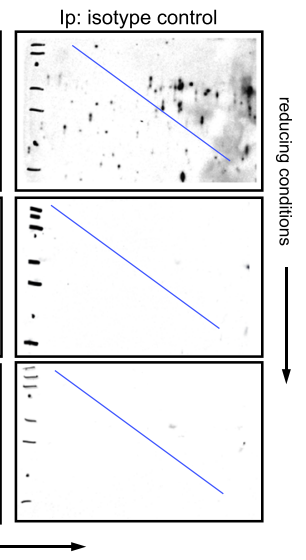

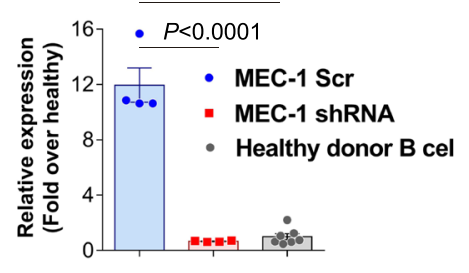

g

PI3K-Akt-mTOR pathway

pArt S473
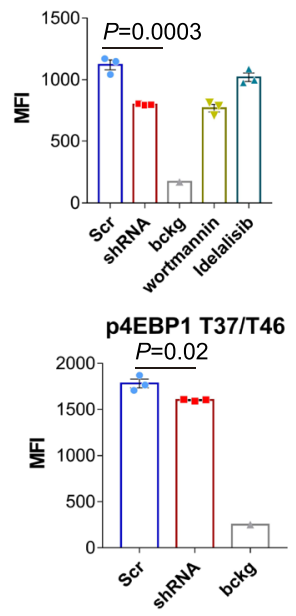

e
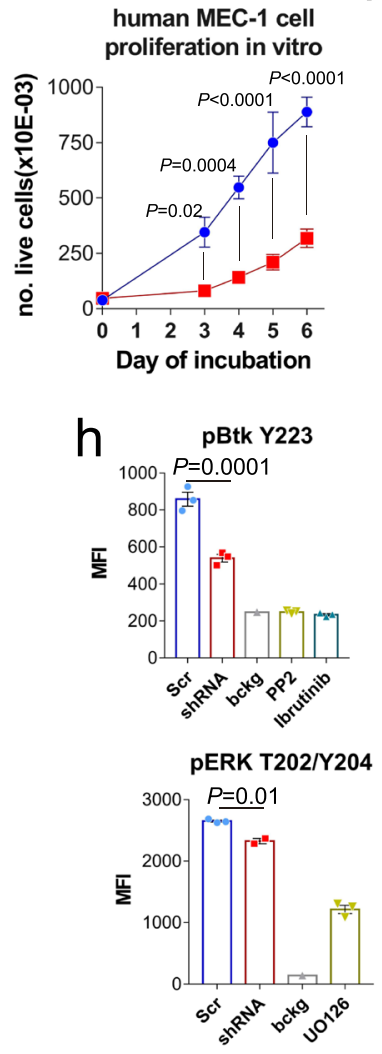

human MEC-1 tumor growth in xenograft
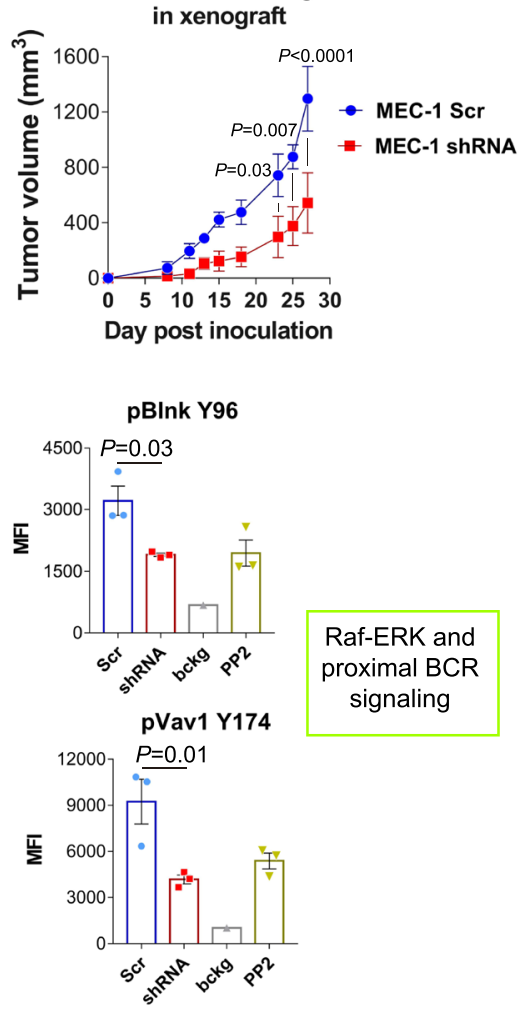

Fig. 4 (See legend on previous page.) 
associated to the BCR in leukemic cells. To this end, we biotin-labelled all plasma membrane proteins of purified CD19+CD5+ leukemic cells from spleens of Rosa26-RRAS2xmb1-Cre mice using a membraneimpermeable biotinylation reagent and immunopurified R-RAS2 protein using an anti-HA antibody. The immunoprecipitates were subjected to two-dimensional SDSPAGE under non-reducing/reducing conditions and immunoblotting was carried out with streptavidin-peroxidase for identification of total membrane proteins co-purifying with R-RAS2. Two biotinylated proteins corresponding in size to the $\operatorname{IgH} \mu$ chain and the $\operatorname{IgL}$ chain were detected (Fig. 4b). Those two proteins were specifically detected with an anti-IgM $(\mathrm{H}+\mathrm{L})$ reactive antibody, thus demonstrating that R-RAS2 is constitutively interacting with the BCR in leukemic cells. By interacting with the BCR, R-RAS2 could be placed just downstream of this receptor in the activation of the PI3K-Akt-mTOR pathway and other canonical BCR signaling pathways (Fig. 4c), as suggested by the RNAseq data (Fig. 4a). Of note, we previously placed R-RAS2 as a direct BCR effector important for the transmission of tonic BCR signals required for survival and homeostatic cell proliferation in the absence of antigen [12]. This property of R-RAS2 aligns with a proposed antigen-independent signaling role for the BCR in CLL [8].

In order to highlight the causal relationship between RRAS2 overexpression and appearance of CLL, we next used the human CLL cell line MEC-1 to determine if R-RAS2 overexpression is required for the activation of BCR signaling pathways and for proliferation and survival of human CLL cells. MEC-1 cells overexpress RRAS2 mRNA at values 12-fold higher than those of B cells from peripheral blood of healthy human donors (Fig. 4d). Transducing MEC-1 cells with a lentiviral construct expressing a shRNA for human RRAS2 reduced the expression of this gene to levels close to those of normal B cells (Fig. 4d). The RRAS2 knockdown MEC-1 cells proliferated more slowly than their control counterparts in vitro (Fig. 4e) and, more importantly, produced smaller tumors than control MEC-1 cells when transplanted subcutaneously into lymphopenic mice (Fig. 4f). These results suggest that high R-RAS2 expression is required for human CLL cell proliferation in vitro and in vivo. Furthermore, the analysis by phosflow cytometry of knockdown and control cells showed that high R-RAS2 expression in MEC-1 cells is required to activate the PI3K-Akt-mTOR (pAkt and p4EBP1) pathway (Fig. 4g), as well as the proximal BCR signaling ( $\mathrm{pBlnk}, \mathrm{pVav1}$ and $\mathrm{pBtk}$ ) and other canonical pathways (MAPK/ERK) (Fig. 4h). Therefore, those data suggest that $R-R A S 2$ expression is mediating $\mathrm{BCR}$ signaling in a human CLL cell line, as well as proliferation in vitro and in vivo.

To determine if R-RAS2 is also mediating BCR signaling in leukemic cells from Rosa26-RRAS2xmb1-Cre mice, we first analyzed those cells by phosflow cytometry in parallel to B cells from WT controls and to B cells from $\operatorname{Rras} 2(\mathrm{Q} 72 \mathrm{~L})^{\mathrm{f} / \mathrm{fl}}$ xmb1-Cre mice, which do not develop CLL (Fig. S6a-f). We found that leukemic B cells overexpressing R-RAS2 present significantly higher activation of the PI3K-Akt-mTOR pathway (pAkt, pS6 and $\mathrm{pEBP} 1$ ) and also higher activation of proximal BCRsignaling (pBlnk) and Raf-ERK pathway (pERK) than normal control follicular B cells (Fig. S6f). Activation of the PI3K-Akt-mTOR, Raf-ERK and BCR signaling pathways was also higher in leukemic B cells than in B1a, B1b and marginal zone (MZ) normal B cells (Fig. S6g), being MZ the $\mathrm{B}$ cell population with the highest constitutive activation of those pathways. In addition, the results of Fig. S6 suggest that $\operatorname{Rras} 2(\mathrm{Q} 72 \mathrm{~L})^{\mathrm{fl} / \mathrm{fl}} \mathrm{xmb1-Cre} \mathrm{mice} \mathrm{express-}$ ing a constitutively active "oncogenic" mutant of R-Rras2 do not develop CLL because they do not activate those $\mathrm{BCR}$ signaling pathways. Rras $2(\mathrm{Q} 72 \mathrm{~L})^{\mathrm{fl} / \mathrm{fl}} \mathrm{xmb1-Cre}$ mice do not develop any detectable malignancy, whereas mice that express the $\operatorname{Rras} 2(\mathrm{Q} 72 \mathrm{~L})$ mutant in all tissues (tamoxifen-regulated Cre-ERT2-regulated mouse strain [iCre-Rras2Q72L]) do develop a form of T-cell acute lymphoblastic leukemia (T-ALL) in $100 \%$ of mice, but not CLL (Fernandez-Pisonero et al., under revision).

\section{Wild-type RRAS2 is overexpressed in human CLL} and correlates with parameters of poorer prognosis Considering that Rosa26-RRAS2xmb1-Cre and Rosa26$R R A S 2 \times$ Sox2-Cre mice develop CLL, that the MEC-1 human CLL cell line overexpresses RRAS2 and that these cells require RRAS2 expression for proliferation and tumor formation, we set out to assess RRAS2 mRNA levels in our own cohort of previously untreated CLL patients to reinforce the metadata (Fig. 1c and S1a) and further analyze the relationship between $R R A S 2$ overexpression and human CLL. In the cohort $(n=178)$, the average age was 69 years and $60 \%$ were males (Table S3). A $63 \%$ were in early stages of the disease, i.e., Binet stage A or Rai stage 0 , and a total of 52 were classified as having a premalignant mononuclear B cell lymphocytosis (MBL) condition, whereas $38 \%$ were IGHV-UM CLL with worse prognosis [40]. Importantly, in line with repository data and correlating with our RRAS2-overexpressing mice, we found a significant increase in RRAS2 mRNA levels in CLL patients compared to healthy subjects, with a mean of 5.3-fold higher expression in CLL patients (Fig. 5a). A classification of patients according to the number of total lymphocytes in blood (Fig. 5b) and the percentage of malignant CD19+CD5+ B cells (Fig. 5c) showed a direct 
correlation with overexpression of $R R A S 2$, i.e., the group of patients with highest lymphocytosis and malignant cell content has the highest overexpression of RRAS2. The classification of patients that present premalignant $\mathrm{MBL}$ versus full-blown CLL is based on the degree of lymphocytosis (threshold at $5 \times 10^{6}$ lymphocytes $/ \mathrm{mm}^{3}$ ). Both conditions occurred upon overexpression of RRAS2, though overexpression in CLL was significantly higher (5.9 fold) than in MBL (3.4 fold, Fig. 5d). Advanced age is another condition of poorer prognosis [40]. We found increased median and mean overexpression of RRAS2 with age in full-blown CLL, but not in MBL (Fig. 5e).

The analysis of RRAS2 expression according to the unmutated vs mutated status of the IgHV region showed a higher mean for the IGHV-UM than for the IGHV-M CLL, although those differences did not reach statistical significance (Fig. 5f). In the subject cohort, most of the samples with unmutated IgHV classified as CLL, not MBL (Fig. 5g). The grouping of leukemias according to MBL, CLL, IGHV-UM and IGHV-M showed that RRAS2 expression correlated with CLL, regardless of IgHV status (Fig. 5h). Another risk factor in CLL is sex, for male patients carry a worse prognosis than female ones [40]. We found that leukemias from male patients had significantly higher expression of RRAS2 than those from female patients (Fig. 5i). A classification of leukemias by fold expression intervals showed that $82 \%$ of all samples overexpressed two-fold or more RRAS2 mRNA than $B$ cells from healthy controls, although the distribution by sex was unequal: $13.6 \%$ of leukemias from male patients expressed lower than 2-fold levels compared to $25.4 \%$ for female patients (Fig. 5j). Conversely, $65.7 \%$ of leukemias from male patients overexpressed 4-fold or more RRAS2 mRNA compared with $55.2 \%$ for female patients. Altogether, these data show that RRAS2 mRNA is overexpressed in the large majority of CLL and that higher expression is associated to factors of worse prognosis such as CLL versus MBL, higher lymphocytosis, advanced age and male sex. The results of human RRAS2 mRNA expression in our cohort of samples (Fig. 5), in repository data (Fig. 1c and S1a), and the effect of RRAS2 overexpression in mouse $\mathrm{B}$ cells driving the development of CLL strongly suggest that overexpression of unmutated RRAS2 also drives the development of human CLL. A comparative RT-qPCR expression analysis of RRAS2 expression in human CLL and in the two mouse models studied here shows that overexpression attained in the mouse systems is within the range of RRAS2 expression levels detected in human leukemias (Fig. 5k), thus reinforcing the idea that the driver role in human CLL is possible.

\section{A single-nucleotide polymorphism (SNP) in the $3^{\prime}$ UTR region of RRAS2 mRNA genetically links overexpression of unmutated RRAS2 with human CLL and more aggressive disease}

Although mutations in the coding sequence of RRAS2 have rarely been found in human cancer, we decided to sequence the RRAS2 mRNA in our cohort of 178 patients. We did not find any missense mutation in the coding sequence. However, in some patients we found a $\mathrm{C}$ nucleotide in position 124 after the stop codon in the 3'UTR, whereas the canonical sequence contains a $\mathrm{G}$ in that position (Fig. 6a). The $\mathrm{C}$ nucleotide at position 124 of the 3'UTR was the previously cataloged SNP rs8570 (from now on, 124C, in this paper). This SNP was identified within a group of SNPs of 26 genes in the MAP kinase pathway to be associated with risk

\footnotetext{
(See figure on next page.)

Fig. 5 RRAS2 expression is increased in CLL patients and associated to more aggressive disease. a Box and whiskers plots showing all points and median value of RT-qPCR data of RRAS2 mRNA expression in PBMCs from healthy individuals and from MBL and CLL patients. Expression data is normalized to the mean value of healthy blood donor values $(n=17)$. Two-tailed unpaired t-test with Welch's correction. $\mathbf{b}$ RT-qPCR analysis of RRAS2 mRNA expression compared to the lymphocyte count in the blood of CLL patients. Patients are classified according the number of total lymphocytes in blood (in ranges, in the $x$-axis). Values represent the mean \pm SEM. All datapoints are represented. One-way ANOVA test. c RT-qPCR analysis of RRAS2 expression compared to the percentage of CD19+CD5+ cells (in ranges in the $x$-axis) in the blood of CLL patients. All datapoints are represented. One-way ANOVA test. $\mathbf{d}$ Box and whiskers plots showing all points and median value of RT-qPCR data of RRAS2 mRNA expression in blood from MBL and CLL patients. Expression data is normalized to the mean value of healthy blood donor values. Two-tailed unpaired t-test with Welch's correction. e Box and whiskers plots showing all points and median values of RT-qPCR data of RRAS2 mRNA expression versus age of the patient at diagnosis (in 10-year intervals) and divided according to the diagnosis as CLL or MBL. One-way ANOVA test. $\mathbf{f}$ Box and whiskers plot showing all points and median value of RT-qPCR data of RRAS2 mRNA expression in CLL patients classified according to the expression of a mutated or an unmutated lgH gene. ns, not significant (two-tailed unpaired t-test with Welch's correction). $\mathbf{g}$ Contigency test of the distribution of mutated and unmutated IgHV gene within MBL and CLL patients in our study cohort. $\mathbf{h}$ Box and whiskers plot showing all points and median value of RT-qPCR data of RRAS2 mRNA expression in our study cohort classified according to MBL vs CLL diagnosis and having mutated or unmutated $\operatorname{lgHV}$. i, Box and whiskers plots showing all points and median value of RT-qPCR data of RRAS2 mRNA expression in blood from all patients in our study cohort classified according to male or female sex. Two-tailed unpaired t-test with Welch's correction. $\mathbf{j}$ Pie chart diagram of the relative fold variations in the expression of RRAS2 mRNA in male and female CLL patients, classified in fold intervals. 1 is the mean of expression in healthy blood donors. $\mathbf{k}$ Box and whiskers plot showing all points and median value of RT-qPCR RRAS2 mRNA expression in blood from healthy individuals and CLL patients, and in spleen B cells from control mice, mb1-Cre mice, and Sox2-Cre mice. One-way ANOVA test). In all panels, when there is no distinction between MBL and CLL patients, CLL refers to both groups
} 
a

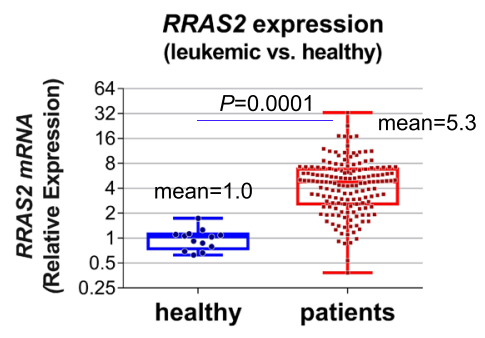

d

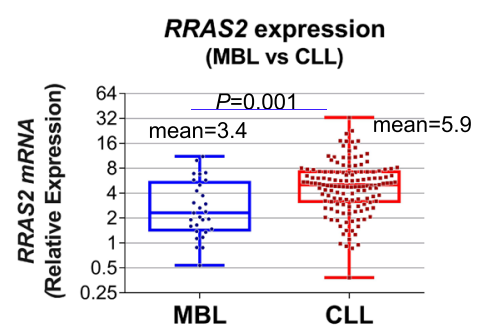

f

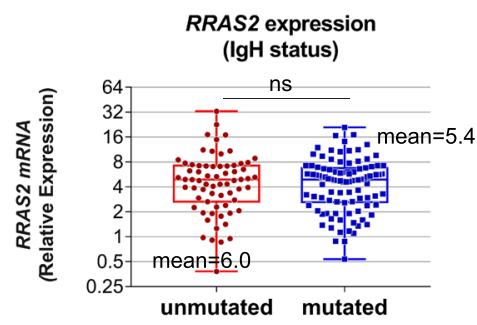

i

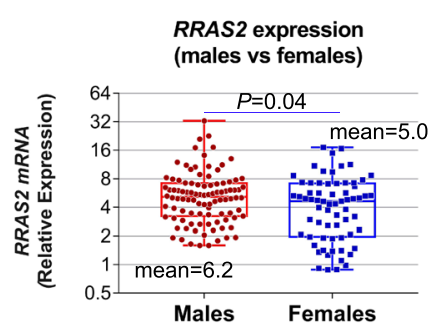

$\mathrm{k}$

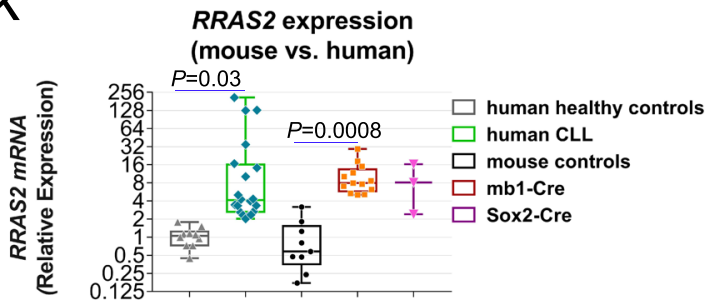

b

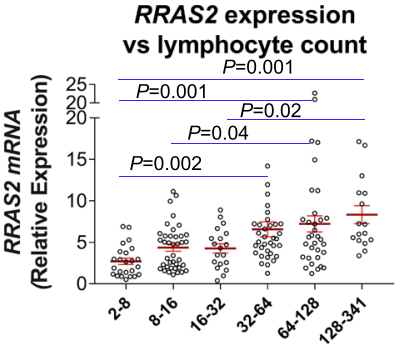

no. lymphocytes (x 10E9)
C

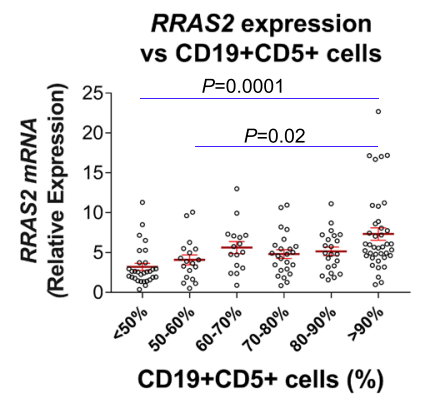

e

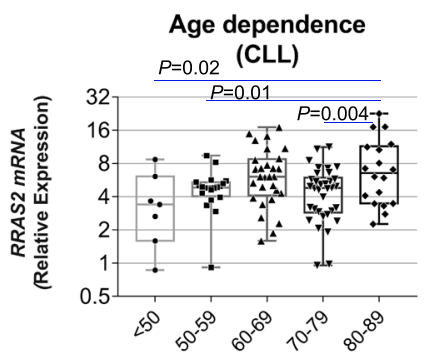

Age range (years)

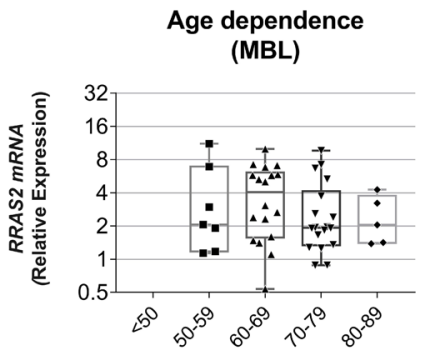

Age range (years)
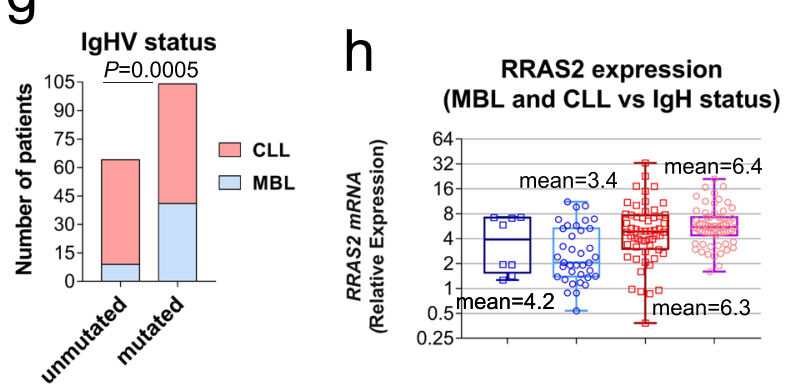

$\square$ MBL unmutated

$\square$ MBL mutated

$\square$ CLL unmutated

$\square$ CLL mutated

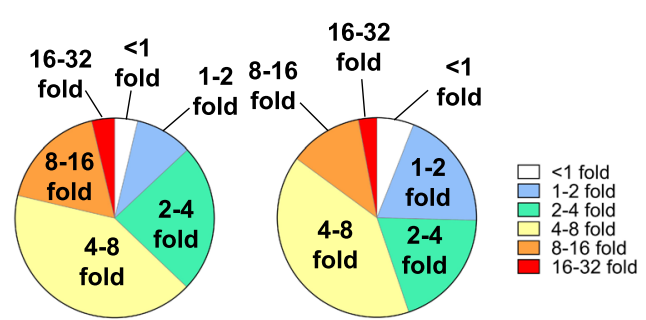

Males

Females

Fig. 5 (See legend on previous page.) 
of cutaneous melanoma [41]. The 124C SNP was first detected in homozygosity or heterozygosity by Sanger DNA sequencing (Fig. 6b) but later was reassessed by a RT-qPCR method using primers with mismatching positions (Fig. 6c, Methods). Using this double procedure, we calculated the frequency of GG homozygotes at position 124 of the 3'UTR in $51 \%$ of the CLL samples, $33 \%$ for GC heterozygotes and $15 \%$ for CC homozygotes. Thus, the frequency of the non-canonical $124 \mathrm{C}$ allele in the CLL cohort is of $32 \%$, slightly above the $22 \%$ frequency measured in the general European population (ALFA project; https://www.ncbi.nlm.nih. gov/snp/rs8570\#frequency_tab). Within our cohort of CLL patients, and according to the frequencies of GG, GC and CC genotypes at position 124, we observed a higher-than-expected frequency of $\mathrm{CC}$ homozygotes and lower frequency for the GC heterozygotes (Fig. 6d). The difference between Observed and Expected values indicates that the distribution of alleles is not in a Hardy-Weinberg equilibrium [42] ( $x^{2}$ experimental $=9.62>\chi^{2}$ theoretical $\left.=3.84 ; p<0.005\right)$. The CC genotype correlated with the highest expression of RRAS2 mRNA, whereas expression in leukemias of the GG phenotype was significantly lower than the ones of the CC genotype (Fig. 6e). Since the size of the CC group is small and mean RRAS2 mRNA expression was very similar between the GC and CC groups, we decided to combine both groups for further analysis. The combined $\mathrm{CC}+\mathrm{GC}$ group expressed significantly higher levels of RRAS2 mRNA than the GG one (Fig. 6f). This correlated with indicators in CLL patients' blood of more aggressive disease, such as total number of lymphocytes (Fig. 6g), higher percentage of B cells
(Fig. 6h), higher percentage of leukemic CD19+CD5+ cells (Fig. 6i) and lower number of platelets (Fig. 6j). The combined $\mathrm{CC}+\mathrm{GC}$ group was significantly more represented in patients with full-blown CLL at diagnosis than in those with MBL (Fig. 6k). Several genetic alterations detected by FISH are prevalent among CLL patients, reflecting varying degrees of association with disease prognosis [43]. The presence of one or two C alleles was more common within the group of patients with chromosomal alterations determined by FISH than those with no alterations (Fig. 6l). Taking together the frequencies of deletions found in chromosome arms $11 q$ and $17 p$, there is a significant association of those alterations with the presence of one or two $124 \mathrm{C}$ alleles (Fig. 6m). Chromosome arm 11q encodes for ATM and chromosome arm 17p encodes for TP53. Loss of any of those tumor suppressor genes is associated with poorer prognosis. We also searched for associations between the expression of the $124 \mathrm{C}$ allele and CLL bearing mutated or unmutated IgHV. We did not find any association between the frequency of IGHV-UM in the GG and $\mathrm{CC}$ groups of the cohort. However, the presence of one $124 \mathrm{C}$ allele (GC heterozygotes) compared to two 124G alleles (GG homozygotes) is also significantly associated to IGHV-UM (Fig. 6n). Finally, we found a clear association between male sex and the frequency of GC and CC (Fig. 6o). Expression of an unmutated IgHV and male sex are two additional factors of poorer prognosis [40]. Therefore, the SNP at position 124 of the $3^{\prime}$ UTR of RRAS2 mRNA emerges as a novel prognostic factor of CLL progression and genetically proves a cause-effect relationship between RRAS2 overexpression and human CLL.

(See figure on next page.)

Fig. 6 The C allele at SNP rs8570 is associated with several parameters of more aggressive disease in CLL patients. a Schematic representation of the rs 8570 location in the 3'UTR of RRAS2 mRNA. $\mathbf{b}$ Representative examples of the Sanger sequencing chromatograms showing the 3 possibilities of allele dosage at the position of $\mathrm{r} 8570$. The $\mathrm{r} 8570$ position is highlighted by a red rectangle. $\mathbf{c}$ Classification of patient samples according to the genotype at SNP rs8570 detected by a dedicated RT-qPCR strategy using specific primers for each of the 2 alleles at that position. The patients sequenced as GG, GC or CC with Sanger sequencing are plotted with dark blue, purple and orange dots, respectively. $\mathbf{d}$ Pie chart representation of the Observed versus the Expected distribution of GG, GC and CC genotypes at position of the SNP rs8570 in our study cohort of CLL patients. e Box and whiskers plots showing all points and median value of RT-qPCR RRAS2 mRNA expression in blood from all patients in our study cohort classified according to GG, GC or CC genotype at position of the SNP rs8570. Ttwo-tailed unpaired t-test with Welch's correction. $\mathbf{f}$ Box and whiskers plots showing all points and median value of RT-qPCR RRAS2 mRNA expression in blood from all patients in our study cohort harboring none (GG) or at least one (GC and CC) 124C at position of the SNP rs8570. Two-tailed unpaired t-test with Welch's correction. $\mathbf{g}$ Box and whiskers plots showing all points and median value of total lymphocyte count in the blood of patients harboring two $G$ alleles or at least one $C$. Two-tailed unpaired t-test with Welch's correction. $\mathbf{h}$ Box and whiskers plots showing all points and median value of the percentage of CD19+ B cells in the blood of patients harboring two G alleles or at least one C. Two-tailed unpaired t-test with Welch's correction. i Box and whiskers plots showing all points and median value of the percentage of CD19+CD5+ leukemic B cells in the blood of patients harboring two G alleles or at least one C. Two-tailed unpaired t-test with Welch's correction. $\mathbf{j}$ Box and whiskers plots showing all points and median value of the platelet count in the blood of patients harboring two $\mathrm{G}$ alleles or at least one C. Two-tailed unpaired t-test with Welch's correction. $\mathbf{k}$ Contigency test of the distribution of patients diagnosed as having MBL or CLL according to a GG or GC+CC genotype. I Contigency test of the distribution of all samples in our study cohort according to presenting or not chromosomal alterations by FISH and a GG or GC + CC genotype. $\mathbf{m}$ Contigency test of the distribution of samples in our study cohort according to presenting normal caryotype or presenting deletions in chromosome 11q or in chromosome 17p (or both) and a GG or $\mathrm{GC}+\mathrm{CC}$ genotype. $\mathbf{n}$ Contingency test of the distribution of all samples in our study cohort according to presenting or not mutated lgHV and a GG or GC genotype. $\mathbf{o}$ Contingency test of the distribution of all samples in our study cohort according to male or female sex and a GG or GC + CC genotype 

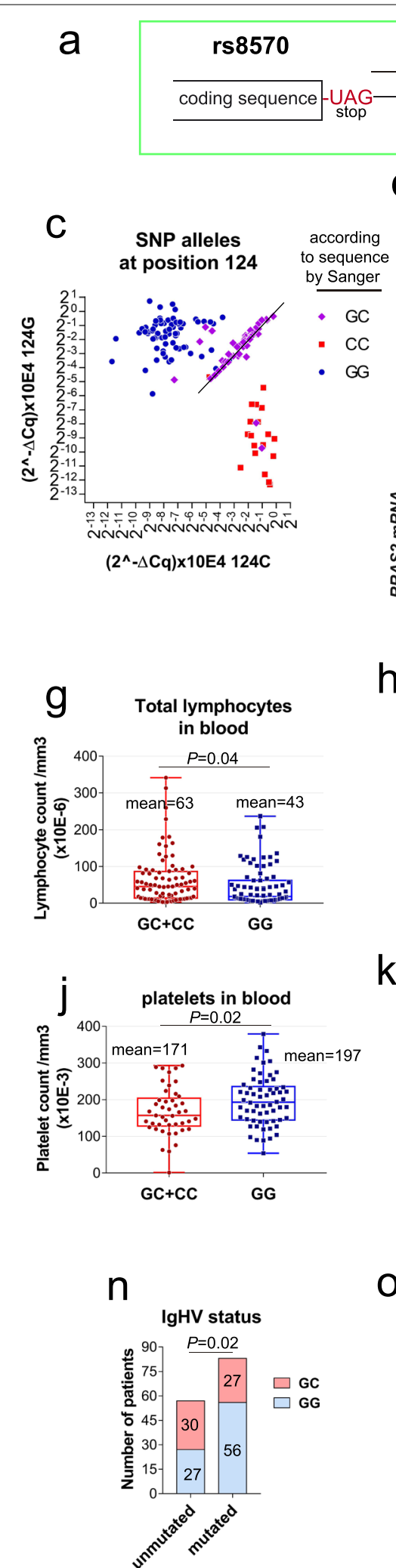

\section{0}

b 3'-UTR 124
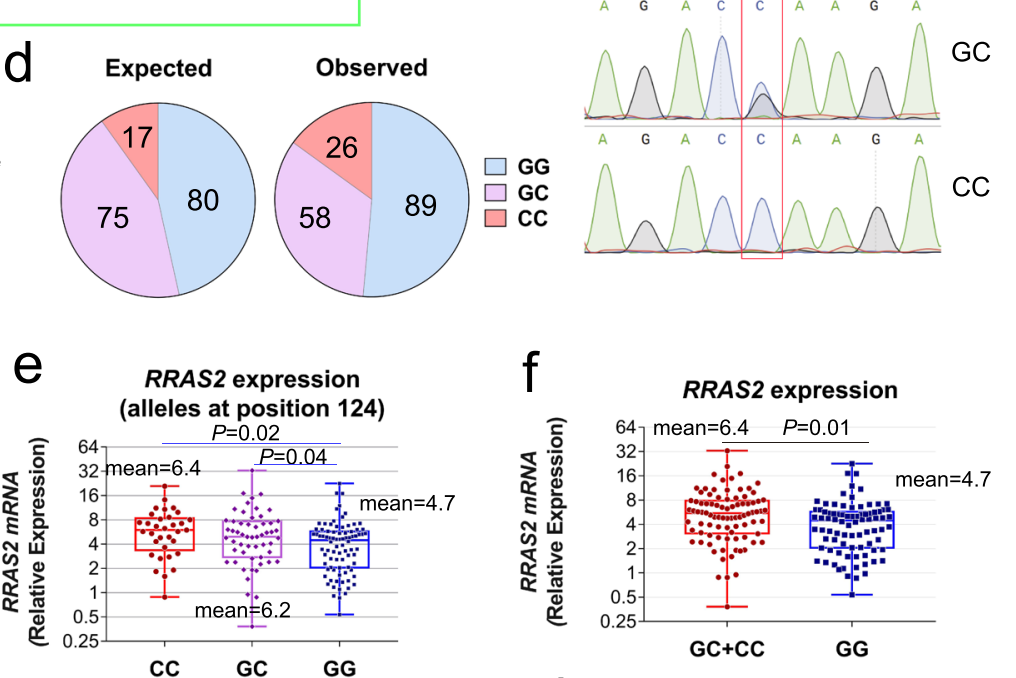

$\mathrm{h}$
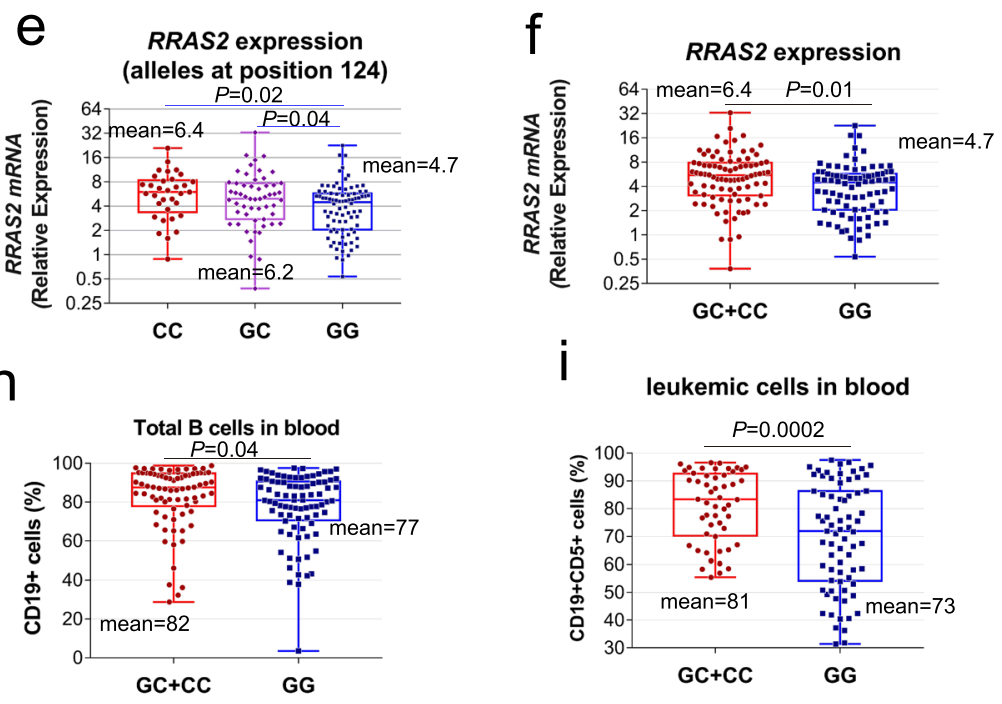

i

leukemic cells in blood

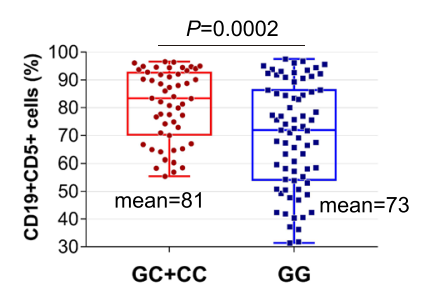

$\mathrm{k}$
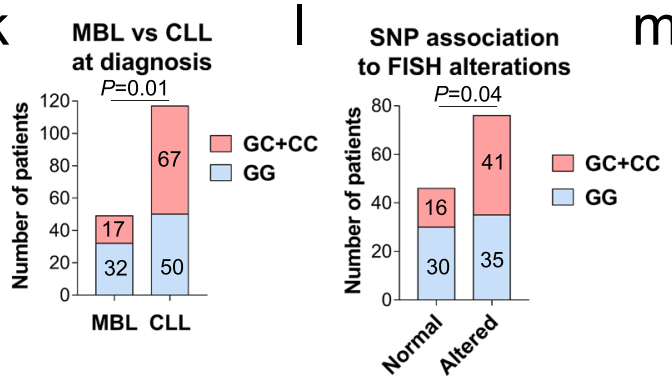

M SNP association to deletions in $11 q$ or $17 p$

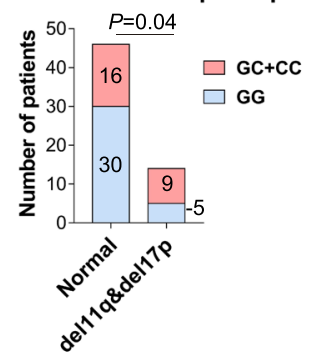

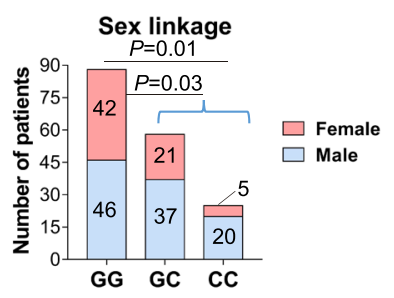




\section{Discussion}

Oncogenic mutations in KRAS or NRAS have been found, though in reduced numbers of CLL patients (32 out of 1308, https://www.cbioportal.org/), and no mutations have been so far identified by GWAS in HRAS or RRAS2. Therefore, $97.5 \%$ of human CLL appear without oncogenic mutations in known RAS drivers. We suggest here that overexpression of wild-type $R R A S 2$, and not activating mutations in RAS members, is what drives transformation of mature B cells towards CLL, at least in $82 \%$ of these leukemias. Against the current view that RAS family members cause cancer after acquiring activating mutations, we show here that RRAS2 does not require activating "oncogenic" mutations in its coding sequence to induce cancer. Instead, we show in a mouse model that overexpression of the wild-type form of human RRAS2 drives the development of a CLL in $100 \%$ of mice. This is a cause-effect relationship that demonstrates that overexpression of wild type RRAS2 is sufficient for the development of CLL in mice and suggest that $82 \%$ of the human CLL are caused by RRAS2 overexpression. In this regard, we have found significant correlations between the highest expression of $R R A S 2$ in patients and relevant indicators of more aggressive disease such as number of lymphocytes in blood, percentage of leukemic cells, age dependence, male sex and CLL versus MBL. Those correlations support the notion that overexpression of RRAS2 is important for the course of the disease in humans. The relevance of $R R A S 2$ overexpression has been proven here by generating an RRAS2 knockdown variant of the CLL human cell line MEC-1, which shows impaired capacity to proliferate in vitro and to form tumors in vivo. Nonetheless, and further reflecting a driver role for wild-type RRAS2 overexpression in human CLL, SNP rs8570 in the 3'UTR of RRAS2 is associated with poorer prognosis and higher RRAS2 expression. At present, we have not elucidated the mechanisms that lead CLL patients that are heterozygous or homozygous for the rs8570 SNP to express more mRNA for RRAS2. However, as this SNP appears at the 3'UTR of the RRAS2 locus, we could hypothesize that higher mRNA in patients bearing the SNP rs8570 is due to resistance to a miRNA. In this regard, it has been described that miR-23b inhibits metastasis of colon carcinoma cells by downregulating $R R A S 2$, among other genes [44], and miR-4448 was identified in a screening of miRNA expression in B cell malignancies versus normal B cells [45]. miR-23b binds the 3'UTR of RRAS2 near the rs8570 SNP site, whereas miR4448 is predicted to interact with the $3^{\prime}$-UTR sequence at the SNP site with a score of 68 (http://www.mirbase.org). However, the participation of those or other miRNAs in differential regulation of RRAS2 mRNA expression warrants further investigation.
Interestingly, we show here that overexpression, and not oncogenic mutation (the Q72L mutant) of RRAS2 drives the formation of CLL in mice. This correlates with the absence of RRAS2 missense mutations identified in human CLL both in databases and in our own cohort of 178 patients, as well as with the overexpression of at least 2-fold the normal levels of RRAS2 mRNA in $82 \%$ of the human samples (mean and median of approximately 5-fold over healthy controls). Our previous data with Rras2-null mice indicate that Rras2 is haploinsufficient, since mice heterozygous for the null allele $\left(\operatorname{Rras}^{+/-}\right)$had the phenotype of the full knockout $\left(\operatorname{Rras}^{-2^{--}}\right)$and not of the wild type $\left(\operatorname{Rras}^{2^{+/+}}\right)$[12]. In fact, heterozygous mice expressed approximately half the amount of protein in their lymphoid cells than wild-type mice. Rras $^{-1-}$ and Rras $^{+/-}$mice have reduced numbers of follicular and marginal zone B cells due to deficient survival and homeostatic proliferation. The haploinsufficiency of Rras 2 and the B cell phenotype suggest that the total amount of R-RAS2 is tightly regulated and therefore, overexpression of RRAS2 by two-fold, or more, in human CLL could be relevant for the human disease.

To our understanding, this is the first report demonstrating a driver role for a RAS-family member in its wild type form. Numerous studies have indicated a tumor suppressor effect of the wild type allele when in the presence of a mutant RAS allele frequently seen as a loss of heterozygosity ( $\mathrm{LOH}$, reviewed in [46], whereas some have reported an enhancing protumorigenic effect of the wild type allele but always in the presence of the mutated, oncogenic, one. Other studies have also shown that overexpression of NRAS promotes the development of lymphomas that are however induced by the use of chemical agents, not just overexpression of the RAS gene [47]. A more recent report has shown that increased expression of wild type KRAS in hematopoietic cell precursors leads to expansion of $B$ cells but not to leukemia probably due to an exhaustion effect [48]. We explain this capacity of wild-type $R R A S 2$ to drive the formation of leukemias by its high guanosine nucleotide intrinsic exchange rate, higher than that of classic RAS proteins [49]. This high exchange rate in the absence of GEF regulators means that wild-type R-RAS2 protein is in the active GTPbound state in the absence of stimuli, i.e., in basal conditions. The elevated intrinsic GDP/GTP exchange rate would be responsible for the high transformation capacity of wild-type RRAS2 in the NIH-3 T3 fibroblast focusformation assay [49] and for the need to keep R-RAS2 protein expression tightly regulated [12].

Perhaps one of the most interesting findings in the murine Rosa26-RRAS2xmb1-Cre model of CLL is the strong convergent evolution of accompanying mutations in leukemic cells from different animals in $50 \%$ or $100 \%$ of the mRNA sequences. This evolution is manifested by 
mutations acquired in tumor suppressor genes that have also been recurrently identified in human CLL and other $\mathrm{B}$ cell leukemias and lymphomas. Those genes include some involved in DNA repair (ATM, ARID1A, SMARCA2, HERC2) chromatin remodeling (ARID1A, ANKRD11, SMARCA2), and transcriptional repressors (SPEN, TET2, $S P 140$ ). By contrast, a pathway that is clearly upregulated in the murine RRAS2-overexpression models of CLL is the PI3K-mTOR pathway, which is detected by both the effect on gene transcription and by the analysis of phosphorylation of key members of the pathway. This upregulation of the pathway was somewhat expected, given the ability of R-RAS2 to recruit the catalytic subunit of PI3K $\delta$ and activate the PI3K pathway in normal B cells [50, 51].

We also show here that R-RAS2 protein is directly interacting with the BCR in murine CLL and that BCR signaling is enhanced, as determined by phosflow analysis of BCR-proximal effector proteins and by the effect on gene transcription. Interestingly, one of the genes found mutated in all analyzed samples of murine CLL, and also found mutated in human CLL, is CD22, which is a negative regulator of $\mathrm{BCR}$ signaling [52]. Thus, our data reinforce the notion that activated or deregulated $\mathrm{BCR}$ signaling is behind the development of CLL as seems also manifested by the overabundance of $\mathrm{VH}$ families that have been shown to be enriched in autoreactive BCRs.

Another finding that favors the idea of evolution of cell populations is the upregulation of RRAS2 (and GFP) expression in the murine Rosa26-RRAS2 models. We still do not know the molecular mechanism that results in what appears to be a shift from approximately 2 -fold overexpression of RRAS2 to a mean of 30-fold overexpression. The two clearly distinct cell populations (GFP low and GFP ${ }^{\text {high }}$ ) suggest the activation or loss of a single regulator of $R R A S 2$ expression resulting in the shift. Whatever the mechanism, it is clear that the initial advantage provided by moderate RRAS 2 overexpression is followed by the selection of cells with the highest expression of R-RAS2 that progressively dominate the leukemic cell population with age. This shift in R-RAS2 expression is accompanied by the expression of typical leukemic markers and by stronger activation of BCR-dependent pathways. Interestingly, a time-wise dependence of RRAS2 overexpression is also observed in human patients with full-blown CLL, with overexpression peaking (approximately 30 -fold) in the oldest human patients, $>80$ years old. Ideally, demonstrating this evolution and selection would require measuring RRAS2 expression along several years in the same untreated individual patients.

In addition to CLL, RRAS2 mRNA is found overexpressed in other hematological malignancies as well as carcinomas, including non-Hodgkin's lymphoma, liver hepatocellular carcinoma, and squamous carcinomas of the lung, head, and cervix (PCAWG cohort, Fig. 1C). These data correlate with higher levels of R-RAS2 protein found through immunohistochemical analysis of lymphomas, squamous carcinomas of the oral cavity and esophagus [18, 19], and also lung cancer (our unpublished data). Therefore, we would expect Rosa26-RRAS2xSox2Cre mice overexpressing R-RAS2 in all tissues to develop additional types of cancer. This research together with the finding of the association of RRAS2 expression levels, and the SNP rs8570, with poorer prognosis in CLL could place RRAS2 both as a prognosis marker in different human cancers and as a molecular target for direct inhibitors, similarly to cancers with mutations in KRAS (reviewed in [53]).

\section{Conclusions}

In summary, we show that overexpression of the wild type form of a rather neglected oncogene, $R R A S 2$, is behind the development of the most frequent leukemia (CLL) in the western world. Its deliberate overexpression in a mouse model provokes the development of the leukemia, thus demonstrating a cause-effect relationship. In addition, it is very frequently found overexpressed in human CLL; with higher overexpression associated with more lymphocytosis, with advanced age and with male sex, all conditions of more aggressive disease. The cause-effect relationship between $R R A S 2$ overexpression and CLL is reinforced by the finding that a SNP in the 3'UTR of the RRAS2 mRNA is associated with more lymphocytosis, fewer platelets, chromosomal aberrations and with full-blown disease. Mechanistically, we find that R-RAS2 protein is physically and functionally associated to the BCR, being important for the activation of the PI3K-Akt-mTOR and other BCRdriven pathways, thus linking R-RAS2 with a previously known player in CLL cell survival and proliferation. We believe this study brings to light an important driver in human cancer which, unlike better known RAS members, does not require to bear oncogenic mutations to provoke cancer and can become itself a drug target for the treatment of CLL and probably other cancers.

\section{Abbreviations}

CLL: Chronic lymphocytic leukemia; R-Ras2: RAS-related member 2; BCR: B-cell antigen receptor; $3^{\prime}$-UTR: 3 untranslated region; SNP: Single-nucleotide polymorphism; PI3K: Phosphatidylinositol 3-kinase; mTOR: Molecular target of rapamycin; IgHV: Variable region of the immunoglobulin heavy chain.

\section{Supplementary Information}

The online version contains supplementary material available at https://doi. org/10.1186/s12943-022-01496-x.

Additional file 1: Figure S1. a, Relative mRNA expression of RRAS2 in different types of leukemia. Data comes from (Haferlach et al., 2010) and has been retrieved from www.oncomine.org. $\mathbf{b}$, Schematic representation 
of the overexpression cassette inserted into the Rosa26 locus. c, Relative expression of RRAS2 measured by RT-qPCR in different organs of Rosa26RRAS2 ${ }^{\text {f/fl }} \times \mathrm{So} \times 2-\mathrm{Cre}$ (Sox2-Cre+) mice compared to that of WT C57BL/6 J Control mice using $18 \mathrm{~S}$ as the reference gene. All expression numbers were normalized to those of liver from WT Control mice $($ mean $=1)$. Data show relative expression of RRAS2 in the indicated organs in $n=3-4$ 8 month-old independent mice. $\mathbf{d}$, Quantification of spleen weight from control and 6 month-old Sox2-Cre + mice. Data shown correspond to four control mice and eleven Sox2-Cre mice. Two-tailed unpaired t-test with Welch's correction. e, Two-parameter flow cytometry of the expression of CD5 and IgM in B cells in the spleen of 6 month-old control and Sox2Cre + mice. $\mathbf{f}$, Quantification of the number of CD5 + IgM+ B cells in the spleens and bone marrow of 6 month-old control and Sox2-Cre + mice. Data correspond to triplicate measurements of one control and three Sox2-Cre mice. Unpaired t-test with Welch's correction. g, Quantification of the serum IgM concentration in the blood of 35-40 wk-old control $(n=3)$ and mb1-Cre $(n=8)$ mice by ELISA. Unpaired t-test with Welch's correction. $\mathbf{h}$, Representative images from Giemsa stainings of blood smears of 36 wk-old control and mb1-Cre mice. i, Two-parameter flow cytometry of the forward scatter and CD5 expression in CD19+ cells in the blood of 16 wk-old mb1-Cre mice. The gated population represents large cells. j, Two-parameter flow cytometry of CD5 expression and BrdU incorporation in CD19+ cells in the blood of 16 wk-old mb1-Cre mice. k, Quantification of the percentage of CD19+ cells that are CD5+ blasts and of the CD19+ CD5+ cells that have incorporated BrdU.

Additional file 2: Figure S2. a, Flow cytometry analysis of GFP populations in 23 wk-old Rosa26-RRAS2 ${ }^{\mathrm{f} / \mathrm{f}} \times \mathrm{S}$ Sox2-Cre mouse spleen. Representative two-color contour plots of GFPhigh and GFPlow populations in total B cells (CD19+), CD5+ leukemic and CD23+ follicular B cells. Bottom, representation of GFP populations in T lymphocytes (CD3+). b, Percentage of GFPhigh cells in the indicated populations determined by flow cytometry. Data show means \pm SEM from $n=8$ mice (23 wk-old mice). ${ }^{* * *} p<0.0001$ (one-way ANOVA test). c, Western blot analysis of R-RAS2 expression of sorted GFPlow and GFPhigh leukemic cells from the spleen of a 25 wk-old Rosa26-RRAS2 $2^{\mathrm{f} / f / \mathrm{l}} \times$ Sox2-Cre mouse ( $\beta$-actin as loading control). d, Dot plot representation of GFPlow $C D 5+$ leukemic B cell evolution in mb1-Cre mice over time, showing each mouse individually $(n=14)$. Data points were adjusted to a linear fit. These data were retrieved from the same mice as in Fig. 2i. e, Percentage of CD5 + cells in the indicated populations comparing GFPhigh and GFPlow distribution. Data show means \pm SEM from $n=4$ 30 wk-old mice. Two-way ANOVA test. $\mathbf{f}$, Heatmap of RNAseq expression data showing the genes differentially regulated in wild-type, follicular $B$ cells $(n=6,12$ wk-old), leukemic CD19+CD5+B cells $(n=6,54$ wk-old), CD19+ GFPhigh ( $n=2,54$ wk-old) and CD19+ GFPlow $(n=2,54$ wk-old $)$ populations. Only genes significantly different between GFPhigh GFplow populations $(p<0.05)$ and with a difference of 2 -fold or more were used. Gene expression is shown in normalized log2 fold change.

Additional file 3: Figure S3. a, Representative two-color contour plots of $B$ cell populations in a peritoneal wash and the spleen of 12 wk-old mice according to the expression of the CD11b and CD5 markers in the CD19+ population. The blue square indicates $C D 11 b+C D 5-B 1 b$ cells in the peritoneum. Red square, the presence of $\mathrm{CD} 11 \mathrm{~b}+\mathrm{CD} 5+\mathrm{B} 1$ a cells in control mice and leukemic cells. Quantification of CD11b + CD5 + cells is shown to the right in box and whiskers plots showing all points and median value. ${ }^{* *} p<0.01$; ${ }^{* * *} p<0.001$, two-tailed unpaired t-test with Welch's correction. $\mathbf{b}$, Representative two-color contour plots of IgM and GFP expression within the $\mathrm{CD} 11 \mathrm{~b}+\mathrm{CD} 5+$ populations shown in $\underline{\mathrm{a}}$. Quantification of Ig $\mathrm{M}^{\text {bright }}$ cells within the CD11b + CD5 + B cell population is shown to the right in box and whiskers plots showing all points and median value. ${ }^{* * * *}$ $p<0.0001$, two-tailed unpaired t-test with Welch's correction.

Additional file 4: Figure S4. a, Representative two-color contour plots of lymphoid populations in liver and spleen from 2 wk-old mice according to the expression of CD19 and CD5 and within the CD19+CD5+ population according to the expression of CD21, B220, CD24, CD23 and CD38 markers. $\mathbf{b}$, Column plots show the quantification of the percentage of CD19+CD5+ B cells in liver and spleen bearing the markers shown in a. $n=4$ mice per group. ${ }^{* *} p<0.01{ }^{* * *} p<0.0001$, ns, not significant (oneway ANOVA test).
Additional file 5: Figure S5. a, Principal component analysis of CD19+CD21-CD23 + follicular B cells from Rosa26-RRAS2xmb1-Cre mice, CD19+CD21-CD23+ follicular B cells from WT C57BL/6 J mice and of leukemic CD19+CD5+, GFPlow and GFPhigh cells from Rosa26RRAS2xmb1-Cre mice. $\mathbf{b}$, Ingenuity Pathway Analysis (IPA) of differentially expressed genes associated with molecular mechanisms of cancer in leukemic versus normal follicular B cells. Pink-filled symbols: upregulated genes. Green-filled: downregulated genes. Double circle: protein complex; horizontal ellipse: transcription regulator; vertical ellipse: transmembrane receptor, diamond: enzyme; trapezium: transporter; triangle: phosphatase; inverted triangle: kinase; vertical rectangle: $\mathrm{G}$ protein-coupled receptor; circle: other. Black arrows: direct interactions; grey/white arrows: indirect interactions. Relationship labels: A: activation; B: binding; C: causation; CO: correlation; E: expression; EC: enzyme catalysis; l: inhibition; L: molecular cleavage; LO: localization; M: biochemical modification; miT: microRNA Targeting; P: phosphorylation/dephosphorylation; PD: protein-DNA binding; PP: protein-protein binding; PR: protein-RNA binding, RB: regulation of binding; RE: reaction; T: transcription; TR: translocation; UB: ubiquitination.

Additional file 6: Figure S6. a, Mutations found in human cancer involving the RRAS2 gene. Data obtained from cBioPortal (97,250 patients/100669 samples). Refseq: NM_012250. Ensembl: ENST00000256196. CCDS: CCDS7814. Uniprot: RRAS2_HUMAN. Missense mutations (green dots): 36. Truncating mutations (black dots): 6. Splice mutations (orange dots): 5. b, Quantification by RT-qPCR or total mouse (Rras2) and human (RRAS2) mRNA expression in purified splenic CD19+ B cells from Rras2(Q72L) $)^{\mathrm{f} / \mathrm{fl}} \mathrm{xmb1-Cre} \mathrm{(Q72L)} \mathrm{mice} \mathrm{compared} \mathrm{to} \mathrm{purified}$ B CD19+ B cells from control WT C57BL/6 mice and to CD19+CD5+ leukemic $\mathrm{B}$ cells from Rosa26-RRAS2 $2^{\mathrm{f} / \mathrm{Al}} \times \mathrm{mb} 1-\mathrm{Cre}$ mice. Results show data obtained in triplicate normalized to the C57BL/ 6 control for $n=3$ mice per group. All mice were 14 month-old. Data show means \pm SEM for three mice per group. ${ }^{*} p<0.05$; ns. Not significant (one-way ANOVA test). c, Left, quantification by flow cytometry of total B-cell number in spleens of 14 month-old control and Rras2(Q72L $)^{f / f}$ xmb1-Cre mice. Right, two-parameter flow cytometry plot showing frequency of lgM + CD5+ cells within CD19+ splenic B cells of control and Rras2(Q72L ff/fl $\mathrm{xmb} 1-\mathrm{Cre}$ mice. $\mathbf{d}$, Left, concentration of B-cells per microliter in blood of control

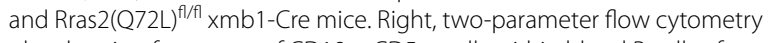
plot showing frequency of CD19+CD5+ cells within blood B cells of control and Rras2(Q72L $)^{f / f l} \mathrm{xmb1-Cre} \mathrm{mice.} \mathrm{e,} \mathrm{Frequency} \mathrm{of} \mathrm{marginal} \mathrm{zone}$ (MZ) phenotype (CD21 high, CD23low), and follicular (CD21 low, CD23high) $B$ cells within CD19+ splenic B cells of control and Rras2(Q72L) $)^{f / f} \times \mathrm{xmb} 1-$ Cre mice. f, Phosflow cytometry analysis of different elements from PI3K-Akt-mTOR, Raf-Erk and proximal BCR signaling pathways. Wild-type CD19+ follicular B cells, CD19+CD5+ leukemic cells from spleens of Rosa26-RRAS2 ${ }^{f / f} \times \mathrm{mb} 1$-Cre mice and CD19+ non-leukemic B cells from $\operatorname{Rras} 2(\mathrm{Q} 72 \mathrm{~L})^{\mathrm{fl} / \mathrm{ll}} \mathrm{xmb1-Cre}$ are shown. In grey, background fluorescence of the secondary antibodies. All mice were 23 wk-old. Data show means \pm SEM from three mice per group. ${ }^{*} p<0.05 ;{ }^{* *} p<0.01 ;{ }^{* * *} p<0.0001$ (one-way ANOVA test). g, Phosflow cytometry analysis of different elements from PI3K-Akt-mTOR, Raf-Erk and proximal BCR signaling pathways. CD19+CD5+ leukemic cells from 30 wk-old Rosa26-RRAS2 $2^{f / f} \mathrm{xmb} 1$ Cre mice are compared with WT Control follicular (CD23 $\left.3^{\text {high }} \mathrm{CD} 21^{-}\right)$, marginal zone (MZ, CD23-CD21 high), B1a (CD11b + CD5+) and B1b $\left(C D 11 b+C D 5^{-}\right)$spleen $B$ cell populations. Data show means \pm SEM from $n=3$ mice per group. ${ }^{* *} p<0.01 ;{ }^{* * *} p<0.001 ;{ }^{* * * *} p<0.0001$; ns, not significant (one-way ANOVA test).

Additional file 7: Figure S7. Ingenuity Pathway Analysis (IPA) of differentially expressed genes associated with mTOR signaling, immunological development, and G1-S checkpoint regulation in leukemic versus normal follicular B cells. Pink-filled symbols: upregulated genes. Green-filled: downregulated genes. Double circle: protein complex; horizontal ellipse: transcription regulator; vertical ellipse: transmembrane receptor, diamond: enzyme; trapezium: transporter; triangle: phosphatase; inverted triangle: kinase; vertical rectangle: $\mathrm{G}$ protein-coupled receptor; circle: other. Black arrows: direct interactions; grey/white arrows: indirect interactions. Relationship labels: A: activation; B: binding; C: causation; CO: correlation; E: expression; EC: enzyme catalysis; I: inhibition; L: molecular cleavage; LO: localization; M: biochemical modification; miT: microRNA Targeting; P: phosphorylation/dephosphorylation; PD: protein-DNA binding; PP: 
protein-protein binding; PR: protein-RNA binding, RB: regulation of binding; RE: reaction; T: transcription; TR: translocation; UB: ubiquitination.

\section{Additional file 8.}

\section{Additional file 9 .}

Additional file 10.

Additional file 11.

\section{Acknowledgements}

We are indebted to Cristina Prieto, Valentina Blanco and Tania Gómez for their expert technical assistance and to Dr. Hisse M van Santen for carefully reading the manuscript.

\section{Authors' contributions}

AMH and CLO carried out most of the phenotyping work and characterization of RRAS2 expression and SNP analysis in human CLL samples. CF carried out PhosFlow analysis and MEC-1 knockdown experiments. MA, ANB and MG characterized and provided clinical samples. IF-P, LC and CG-M processed all mouse samples for histochemical analysis. IF-P, LC and RT generated and analyzed Rras2-Q72L mice, PM, VD and BP generated and bred Rosa26-RRAS2 mice. DA analyzed RNAseq data. XRB and BA conceived the projects and directed research. BA and CLO wrote the manuscript that was edited and revised by $A M H, V D, M A, A N B, M G$ and XRB. The authors read and approved the final manuscript.

\section{Funding}

This work was supported by grants from the Spanish Association against Cancer (GC16173472GARC), PID2019-104935RB-I00 from the 'Comision Interministerial de Ciencia y Tecnologia', the 'Fundación Ramón Areces', and by the European Research Council ERC 2013-Advanced Grant 334763 "NOVARIPP", Instituto de Salud Carlos III (ISCIII) (CIBERONC - groups CB16/12/00233, CB16/12/00351), the Health Council of the Junta de Castilla y León (GRS 2036/A/19) and private Gilead (GLD15/00348). Juan de la Cierva (FJCl-2016-28756).

\section{Availability of data and materials}

The data supporting the conclusions of this article are presented within article and its additional files.

\section{Declarations}

\section{Ethics approval and consent to participate}

All animal experiments were carried out at the facilities of the Centro de Biología Molecular Severo Ochoa in accordance with national and European guidelines. All the procedures were approved by the ethical committee of the Centro de Biología Molecular Severo Ochoa (approval number: ceea-cbmso-16-02-2015). Blood samples from volunteer CLL patients were obtained from the Hematology Unit of the Salamanca University Hospital after providing written informed consent.

\section{Consent for publication}

Written informed consent was obtained from all patients.

\section{Competing interests}

The authors declare that they have no competing interests.

\footnotetext{
Author details

${ }^{1}$ Immune System Development and Function Program, Centro Biología Molecular Severo Ochoa, Consejo Superior de Investigaciones Científicas, Universidad Autónoma de Madrid, 28049 Madrid, Spain. ${ }^{2}$ Savana, S.L., Calle Gran Vía 30, 28013 Madrid, Spain. ${ }^{3}$ Departamento de Hematología, Hospital Universitario de Salamanca (HUS-IBSAL), CIBERONC (CB16/12/00233) y Centro de Investigación del Cáncer -IBMCC (USAL-CSIC), Salamanca, Spain. ${ }^{4}$ Centro de Investigación del Cáncer, Instituto de Biología Molecular y Celular del Cáncer, and Centro de Investigación Biomédica en Red de Cáncer (CIBERONC), CSIC-Universidad de Salamanca, Campus Unamuno s/n, 37007 Salamanca, Spain. ${ }^{5}$ Servicio de Transgénesis CBM-CNB, Centro Nacional de Biotecnología Consejo Superior de Investigaciones Científicas, Darwin 3, 28049 Madrid,
}

Spain. ${ }^{6}$ Bioinformatics Facility, Centro Biología Molecular Severo Ochoa, Consejo Superior de Investigaciones Científicas, Universidad Autónoma de Madrid, 28049 Madrid, Spain.

Received: 8 October 2021 Accepted: 23 December 2021

Published online: 04 February 2022

\section{References}

1. Siegel RL, Miller KD, Jemal A. Cancer statistics, 2017. CA Cancer J Clin. 2017;67:7-30. https://doi.org/10.3322/caac.21387 Epub 2017 Jan 5.

2. Bosch F, Dalla-Favera R. Chronic lymphocytic leukaemia: from genetics to treatment. Nat Rev Clin Oncol. 2019;16:684-701.

3. Hallek M, Shanafelt TD, Eichhorst B. Chronic lymphocytic leukaemia. Lancet. 2018;391:1524-37.

4. Cohen JA, Bomben R, Pozzo F, Tissino E, Härzschel A, Hartmann TN, et al. An updated perspective on current prognostic and predictive biomarkers in chronic lymphocytic leukemia in the context of Chemoimmunotherapy and novel targeted therapy. Cancers. 2020;12:894.

5. Puente XS, Beà S, Valdés-Mas R, Villamor N, Gutiérrez-Abril J, MartínSubero Jl, et al. Non-coding recurrent mutations in chronic lymphocytic leukaemia. Nature. 2015;526:519-24.

6. Burger JA, Chiorazzi N. B cell receptor signaling in chronic lymphocytic leukemia. Trends Immunol. 2013;34:592-601.

7. Herman SE, Sun X, McAuley EM, Hsieh MM, Pittaluga S, Raffeld M, et al. Modeling tumor-host interactions of chronic lymphocytic leukemia in xenografted mice to study tumor biology and evaluate targeted therapy. Leukemia. 2013;27:2311-21.

8. Minden MD, Übelhart R, Schneider D, Wossning T, Bach MP, Buchner M, et al. Chronic lymphocytic leukaemia is driven by antigen-independent cell-autonomous signalling. Nature. 2012;489:309-12.

9. Gary-Gouy H, Sainz-Perez A, Marteau J-B, Marfaing-Koka A, Delic J, MerleBeral $\mathrm{H}$, et al. Natural phosphorylation of CD5 in chronic lymphocytic leukemia B cells and analysis of CD5-regulated genes in a B cell line suggest a role for CD5 in malignant phenotype. J Immunol. 2007;179:4335-44.

10. Graham SM, Cox AD, Drivas G, Rush MG, D'Eustachio P, Der CJ. Aberrant function of the Ras-related protein TC21/R-Ras2 triggers malignant transformation. Mol Cell Biol. 1994;14:4108-15.

11. Graham SM, Oldham SM, Martin CB, Drugan JK, Zohn IE, Campbell S, et al. TC21 and Ras share indistinguishable transforming and differentiating activities. Oncogene. 1999;18:2107-16.

12. Delgado P, Cubelos B, Calleja E, Martinez-Martin N, Cipres A, Merida I, et al. Essential function for the GTPase TC21 in homeostatic antigen receptor signaling. Nat Immunol. 2009;10:880-8.

13. Rong R, He Q, Liu Y, Sheikh MS, Huang Y. TC21 mediates transformation and cell survival via activation of phosphatidylinositol 3-kinase/Akt and NF-kappaB signaling pathway. Oncogene. 2002;21:1062-70.

14. Mendoza P, Martinez-Martin N, Bovolenta ER, Reyes-Garau D, HernansanzAgustin P, Delgado P, et al. R-Ras2 is required for germinal center formation to aid B cells during energetically demanding processes. Sci Signal. 2018;11(532):eaal1506.

15. Larive RM, Abad A, Cardaba CM, Hernandez T, Canamero M, de Alava E, et al. THE Ras-like protein R-Ras2/TC21 is important for proper mammary gland development. Mol Biol Cell. 2012;25:25.

16. Larive RM, Moriggi $G$, Menacho-Márquez M, Cañamero M, de Álava E, Alarcón B, et al. Contribution of the R-Ras2 GTP-binding protein to primary breast tumorigenesis and late-stage metastatic disease. Nat Commun. 2014;5:3881.

17. Clark GJ, Kinch MS, Gilmer TM, Burridge K, Der CJ. Overexpression of the Ras-related TC21/R-Ras2 protein may contribute to the development of human breast cancers. Oncogene. 1996;12:169-76.

18. Sharma R, Sud N, Chattopadhyay TK, Ralhan R. TC21/R-Ras2 upregulation in esophageal tumorigenesis: potential diagnostic implications. Oncology. 2005;69:10-8 Epub 2005 Jul 28.

19. Macha MA, Matta A, Sriram U, Thakkar A, Shukla NK, Datta Gupta S, et al. Clinical significance of TC21 overexpression in oral cancer. J Oral Pathol Med. 2010:39:477-85 Epub 2009 Dec 16.

20. Lee JH, Pyon JK, Lee SH, Lee YJ, Kang SG, Kim CH, et al. Greater expression of TC21/R-ras2 in highly aggressive malignant skin cancer. Int J Dermatol. 2011;50:956-60. https://doi.org/10.1111/j.1365-4632.2010.04846.x. 
21. Thai T-H, Calado DP, Casola S, Ansel KM, Xiao C, Xue Y, et al. Regulation of the germinal center response by MicroRNA-155. Science. 2007;316:604-8.

22. Hayashi S, Lewis P, Pevny L, McMahon AP. Efficient gene modulation in mouse epiblast using a Sox2Cre transgenic mouse strain. Mech Dev. 2002;119:S97-101.

23. Hobeika E, Thiemann S, Storch B, Jumaa H, Nielsen PJ, Pelanda R, et al. Testing gene function early in the $B$ cell lineage in $\mathrm{mb} 1$-cre mice. Proc Natl Acad Sci. 2006;103:13789-94.

24. Komuro K, Itakura K, Boyse EA, John M. Ly-5: a new T-lymphocyte antigen system. Immunogenetics. 1974;1:452-6.

25. Song J, Willinger T, Rongvaux A, Eynon EE, Stevens S, Manz MG, et al. A mouse model for the human pathogen salmonella Typhi. Cell Host Microbe. 2010;8:369-76.

26. Bertilaccio MT, Scielzo C, Simonetti G, Ponzoni M, Apollonio B, Fazi C, et al. A novel Rag2-/-gammac-/--xenograft model of human CLL. Blood. 2010;115:1605-9.

27. Lefever S, Rihani A, Van der Meulen J, Pattyn F, Van Maerken T, Van Dorpe $J$, et al. Cost-effective and robust genotyping using double-mismatch allele-specific quantitative PCR. Sci Rep. 2019;9:2150.

28. Angelin-Duclos $C$, Calame K. Evidence that immunoglobulin $V_{H_{H}}-D J$ recombination does not require germ line transcription of the recombining variable gene segment. Mol Cell Biol. 1998;18:6253-64.

29. Schlissel MS, Corcoran LM, Baltimore D. Virus-transformed pre-B cells show ordered activation but not inactivation of immunoglobulin gene rearrangement and transcription. J Exp Med. 1991;173:711-20.

30. Haferlach T, Kohlmann A, Wieczorek L, Basso G, Kronnie GT, Béné M-C, et al. Clinical utility of microarray-based gene expression profiling in the diagnosis and subclassification of leukemia: report from the international microarray innovations in leukemia study group. JCO. 2010;28:2529-37.

31. Zhou Y, Zhang Y, Han J, Yang M, Zhu J, Jin T. Transitional B cells involved in autoimmunity and their impact on neuroimmunological diseases. J Trans Med. 2020;18:131

32. Theml H, Trepel F, Schick P, Kaboth W, Begemann H. Kinetics of lymphocytes in chronic lymphocytic leukemia: studies using continuous 3H-thymidine infusion in two patients. Blood. 1973;42:623-36.

33. Behar SM, Lustgarten DL, Corbet S, Scharff MD. Characterization of somatically mutated S107 VH1 1-encoded anti-DNA autoantibodies derived from autoimmune (NZB $\times$ NZW)F1 mice. J Exp Med. 1991;173:731-41.

34. Holodick NE, Zeumer L, Rothstein TL, Morel L. Expansion of B-1 a cells with Germline heavy chain sequence in lupus mice. Front Immunol. 2016;7 [cited 2021 Jun 29]. Available from: http://journal.frontiersin.org/Article/ 10.3389/fimmu.2016.00108/abstract.

35. Chen S-S, Batliwalla F, Holodick NE, Yan X-J, Yancopoulos S, Croce CM, et al. Autoantigen can promote progression to a more aggressive TCL1 leukemia by selecting variants with enhanced B-cell receptor signaling. Proc Natl Acad Sci. 2013;110:E1500-7.

36. Hayakawa K, Formica AM, Colombo MJ, Ichikawa D, Shinton SA, BrillDashoff J, et al. B cells generated by B-1 development can progress to chronic lymphocytic leukemia: cellular origin of B-CLL. Ann NY Acad Sci. 2015;1362:250-5.

37. Chang MT, Asthana S, Gao SP, Lee BH, Chapman JS, Kandoth C, et al. Identifying recurrent mutations in cancer reveals widespread lineage diversity and mutational specificity. Nat Biotechnol. 2016;34:155-63. https://doi. org/10.1038/nbt.3391 Epub 2015 Nov 30.

38. Stamatopoulos K, Belessi C, Moreno C, Boudjograh M, Guida G, Smilevska T, et al. Over $20 \%$ of patients with chronic lymphocytic leukemia carry stereotyped receptors: pathogenetic implications and clinical correlations. Blood. 2007;109:259-70.

39. Wortis HH, Teutsch M, Higer M, Zheng J, Parker DC. B-cell activation by crosslinking of surface lgM or ligation of CD40 involves alternative signal pathways and results in different B-cell phenotypes. Proc Natl Acad Sci. 1995;92:3348-52.

40. Gaidano G, Rossi D. The mutational landscape of chronic lymphocytic leukemia and its impact on prognosis and treatment. Hematology. 2017:2017:329-37.

41. Liu H, Wang L-E, Liu Z, Chen WV, Amos Cl, Lee JE, et al. Association between functional polymorphisms in genes involved in the MAPK signaling pathways and cutaneous melanoma risk. Carcinogenesis. 2013;34:885-92.
42. Mayo O. A Century of Hardy-Weinberg Equilibrium. Twin Res Hum Genet. 2008;11:249-56.

43. Zalcberg I, D'Andrea MG, Monteiro L, Pimenta G, Xisto B. Multidisciplinary diagnostics of chronic lymphocytic leukemia: European research initiative on CLL - ERIC recommendations. Hematol Transfus Cell Ther. 2020;42:269-74.

44. Zhang H, Hao Y, Yang J, Zhou Y, Li J, Yin S, et al. Genome-wide functional screening of miR-23b as a pleiotropic modulator suppressing cancer metastasis. Nat Commun. 2011:2:554.

45. Jima DD, Zhang J, Jacobs C, Richards KL, Dunphy CH, Choi WWL, et al. Deep sequencing of the small RNA transcriptome of normal and malignant human B cells identifies hundreds of novel microRNAs. Blood. 2010;116:e118-27.

46. Zhou B, Der CJ, Cox AD. The role of wild type RAS isoforms in cancer. Semin Cell Dev Biol. 2016;58:60-9.

47. Diaz R. Complex effects of Ras proto-oncogenes in tumorigenesis. Carcinogenesis. 2003;25:535-9.

48. Sasine JP, Himburg HA, Termini CM, Roos M, Tran E, Zhao L, et al. Wildtype Kras expands and exhausts hematopoietic stem cells. JCI Insight. 2018:3:e98197.

49. Movilla N, Crespo P, Bustelo XR. Signal transduction elements of TC21, an oncogenic member of the R-Ras subfamily of GTP-binding proteins. Oncogene. 1999;18:5860-9.

50. Okkenhaug K, Ali K, Vanhaesebroeck B. Antigen receptor signalling: a distinctive role for the p110delta isoform of PI3K. Trends Immunol. 2007;28:80-7 Epub 2007 Jan 5.

51. Rodriguez-Viciana P, Sabatier C, McCormick F. Signaling specificity by Ras family GTPases is determined by the full spectrum of effectors they regulate. Mol Cell Biol. 2004;24:4943-54.

52. ten Hacken E, Burger JA. Microenvironment interactions and B-cell receptor signaling in chronic lymphocytic leukemia: implications for disease pathogenesis and treatment. Biochimica et Biophysica Acta (BBA) - molecular. Cell Res. 2016;1863:401-13.

53. Tang D, Kroemer G, Kang R. Oncogenic KRAS blockade therapy: renewed enthusiasm and persistent challenges. Mol Cancer. 2021;20:128.

\section{Publisher's Note}

Springer Nature remains neutral with regard to jurisdictional claims in published maps and institutional affiliations.

Ready to submit your research? Choose BMC and benefit from

- fast, convenient online submission

- thorough peer review by experienced researchers in your field

- rapid publication on acceptance

- support for research data, including large and complex data types

- gold Open Access which fosters wider collaboration and increased citations

- maximum visibility for your research: over $100 \mathrm{M}$ website views per year

At $\mathrm{BMC}$, research is always in progress.

Learn more biomedcentral.com/submissions 